Chapter 5

\title{
Marine Flatfish-Derived Bioactive Peptides: From the Ocean to the Bedside
}

\author{
Susan Douglas \\ Additional information is available at the end of the chapter \\ http://dx.doi.org/10.5772/51124
}

\section{Introduction and Relevance}

Infectious diseases and cancer are leading causes of mortality and our ability to combat them is compromised due to the emergence of antibiotic-resistant strains of bacteria and chemotherapy-resistant cancer cells. Combined with the scarcity of new classes of antibiotics due to the abandonment of antibacterial research by pharmaceutical companies (Williams and Bax, 2009) and the lengthy development time lines to market (Projan and Bradford, 2007), there is an urgent need for alternative therapeutics. Cationic antimicrobial peptides (CAPs) have emerged as a promising source of novel therapeutics. Not only do they rapidly kill microbes and cancer cells, they also can modulate host innate immunity to augment clearance of microbes and promote tissue healing resulting from inflammation. Furthermore, they are less prone to resistance than traditional antibiotics (McPhee and Hancock, 2005). Synthetic variants of naturally occurring CAPs, have been designed that exhibit greater selectivity and stability. Here I summarize some of the key features of CAPs, directing the reader to recent pertinent reviews, and focus on characteristics of pleurocidin CAPs that make them attractive for clinical applications.

\section{Physical properties of cationic antimicrobial peptides}

\subsection{Classes}

CAPs are small peptides (10-50 amino acids) with a high content of positively charged (net charge +2 to +9 ) and hydrophobic (up to 50\%) amino acids. Currently over 1800 naturally occurring CAPs from almost all forms of life are annotated in the Antimicrobial Peptide Database (http://aps.unmc.edu/AP/main.php). They can be classified into four structural 
groups: linear $\alpha$-helical, $\beta$-sheet, loop, and extended structures enriched in certain amino acids such as Arg, Phe, Pro, Gly, Trp and His (Zasloff, 2002). Linear $\alpha$-helical CAPs such as magainin, LL-37 and pleurocidin are usually unstructured in aqueous solution but adopt an $\alpha$-helical conformation upon interaction with lipids, thereby acquiring antimicrobial activity. They often contain a hinge in the middle, due to Gly or Pro residues, which enhances the ability of the peptide to enter the cell (Park et al., 2000). CAPs that form stable $\beta$-sheet structures contain cysteine residues that are able to form disulphide bonds (usually 1-4 depending on the type of CAP). These include the protegrins, defensins and drosomycins. Looped CAPs, thanatin and brevinin, contain a C-terminal loop carrying a strong positive charge (Fehlbaum et al., 1996). CAPs such as bactenecin, prophenin and indolicidin are enriched in specific amino acids, usually lack cysteines, and form linear or extended coils. CAPs are usually produced as inactive pre-pro-peptides and proteolytically cleaved to release the mature biologically active peptide.

\subsection{Pleurocidin}

Pleurocidins comprise a family of linear $\alpha$-helical CAPs consisting of a highly conserved amino-terminal signal sequence and a carboxy-terminal anionic segment flanking the more variable mature peptide of approximately 25 amino acids (Douglas et al., 2001; Patrzykat et al., 2003). This anionic portion may counteract the positively charged mature peptide, thereby keeping it inactive until cleaved. They show some sequence similarity to other fish CAPs, including piscidin, moronecidin and the recently discovered gaduscidin (Browne et al., 2011; Sun et al., 2007). Pleurocidins are encoded as clusters of genes comprised of four exons, and binding sites for transcription factors involved in host defense are located upstream of the promoters (Douglas et al., 2003).

Pleurocidin variant NRC-04 is the best-studied of this family of peptides. Early studies showed that in 25\% dodecylphosphatidylcholine (DOPC)/ dodecylphosphatidyl-ethanolamine (DOPE) vesicles, it forms a structure containing between $12 \%$ and $24 \% \alpha$-helical content (Yoshida et al., 2001). Supporting this, it was only weakly incorporated into neutral bilayers composed of a 7:3 mixture of DOPC and DOPE; however, it strongly associated with a slightly anionic bilayer of 7:3:1 DOPC, DOPE, and dodecylphosphatidylserine (DOPS), forming well-defined single ion channels (Saint et al., 2002). NMR studies have shown that in $0 \%$ DPC, pleurocidin has no identifiable well-defined secondary structure but in 30\% TFE and in $10 \mathrm{mM}$ DOPC micelles, it was 25\% $\alpha$-helical and this increased to 95\% in $140 \mathrm{mM}$ DOPC (Syvitski et al., 2005). The hydrophobic amino acids residues clustered on approximately $2 / 3$ of the helix and hydrophilic residues on the remaining $1 / 3$ of the helix.

\section{Distribution and expression of cationic antimicrobial peptides}

\subsection{Organismal distribution}

CAPs are ubiquitous in nature and play a crucial role in first-line host defense against pathogens. Fish and marine invertebrates, because of their diversity and reliance on non- 
specific innate immune defenses, have proved to be a particularly good source of novel CAPs with therapeutic potential (Otero-González, 2010; Smith and Fernandes, 2009).

\subsection{Expression}

\subsubsection{Tissue specificity}

In mammals, CAPs are expressed in cells of the skin and mucosal surfaces, as well as blood cells such as platelets, monocytes/macropages, neutrophils, and mast cells (Guaní-Guerra et al., 2010). Tissues often express a cocktail of different CAPs with varying activities and the expression of a given CAP variant may be restricted to a specific cell type (see Wiesner and Vilcinskas, 2010). For example, of the six different $\alpha$-defensins, four are produced predominantly in neutrophils whereas two are secreted from Paneth cells of the small intestine.

Fish CAPs such as pleurocidin are expressed in a broad range of tissues and cell types including epithelial, immune and blood cells (Browne et al., 2011). Pleurocidin is produced by epithelial cells of the skin and gut (Cole et al., 1997; Douglas et al., 2001) as well as circulating immune cells (Murray et al., 2007). Interestingly, different pleurocidin variants are produced by different cell types (Douglas et al., 2003), underscoring the importance of screening multiple tissues to uncover the true diversity of CAPs.

\subsubsection{Developmental stage}

The presence of CAPs in neonates, who have yet to develop adaptive immunity, provides enteric protection and impacts the composition of the commensal microflora. Milk lactoferrin, from which the CAP lactoferricin is produced by pepsin cleavage in the stomach, plays a major role in maternal and innate immunity (Jenssen and Hancock, 2009). Dermicidin YP-30 is important for maternal and early post-natal protection (Wiesner and Vilcinskas, 2010). Mouse cathelin-related antimicrobial peptide undergoes a developmental switch from constitutive intestinal epithelial expression in neonates to Paneth cell expression in adult intestinal crypts (Menard et al., 2008).

Pleurocidin transcripts were detected early in development of winter flounder, when larvae are most susceptible to pathogen-induced mortality, and showed a progressive increase as development proceeded to adulthood (Douglas et al., 2001). Furthermore, different pleurocidin variants were present at different stages of development, indicating that screening of CAP production from various developmental stages of an organism is an excellent means of discovering novel peptide variants.

\subsubsection{Constitutive or inducible}

CAPs may be expressed constitutively or inducibly in response to stress, poor nutrition, inflammation (Wehkamp et al., 2003), injury or microbial infection (Redfern et al., 2011; Zasloff, 2006), and exposure to environmental factors such as zinc (Talukder et al., 2011) or vitamin D (White, 2010). For example, hCAP-18/LL-37 protein and mRNA expression was up-regulated in neutrophils that had migrated to the inflamed gingival tissues of patients 
with chronic periodontitis (Turkoglu et al., 2011) and mycoplasma infection induces cathelicidin expression in neutrophils of infected mice (Tani et al., 2011). Interestingly, increased endogenous glucocorticoid levels induced by psychological stress reduce CAP expression in mice, leading to increased susceptibility to infection (Aberg et al., 2007).

Expression of fish CAPs is also regulated in response to stress and disease (Douglas et al., 2003a; Sun et al., 2007), and novel variants are often induced by such stressors. Monitoring levels of CAPs in aquaculture settings provides early warning of immunosuppression due to chronic stress, and conversely induction of CAPs provides protection against anticipated stressful situations such as handling (Noga et al., 2011).

\section{Mode of action of cationic antimicrobial peptides}

\subsection{Membrane effects}

CAPs can cause lysis of biological membranes or cross membranes by spontaneous lipid-assisted translocation. The initial interaction is electrostatic between the cationic residues of the peptide and the negatively charged constituents of the target cell, whether they are in an outer bacterial envelope, a viral envelope or a eukaryotic cell membrane. Because of the high proportion of uncharged zwitterionic lipids and sterols in normal eukaryotic membranes, however, these membranes are not as susceptible as negatively charged bacterial membranes or cancer cell membranes, which contain elevated levels of negatively charged sialylated glycoproteins (van Beek et al., 1973), O-glycosylated mucins (Yoon et al., 1996) and phosphatidylserine (Riedl et al., 2011).

Upon binding, the peptide assumes an amphipathic secondary structure that facilitates membrane disruption. A number of mechanisms have been proposed including micelle formation by the carpet model (Shai, 2002) and pore formation by the barrel-stave and toroidal pore models (Brogden, 2005; Hadley and Hancock, 2010). Additional variations on these initial models for bacterial membrane interactions have been proposed including localized membrane disorganization by the aggregate model (Hancock and Rozek, 2002), the formation of disordered toroidal pores, charged lipid clustering, membrane thinning, electroporation, non-lytic membrane depolarization, anion carriers and oxidized lipid targeting (Nguyen et al., 2011).

Pleurocidin has been proposed to act via the toroidal pore model, based on its interactions with model membranes (Saint et al., 2002). This finding is supported by NMR studies that show that in DOPC pleurocidin exists as a very large species, probably composed of 20-25 aggregating molecules (Syvitski et al., 2005), indicating that at high concentrations pleurocidin forms pores within the membrane environment or disrupts the membrane by aggregation. A more recent study proposed that CAPS similar to pleurocidin such as magainin 2 adopt a surface alignment in mixed zwitterionic/anionic membranes and forms disordered toroidal pores (Leontiadou et al., 2006). The interaction of pleurocidin with the anionic lipid phosphatidylglycerol (PG) rather than the zwitterionic lipid phosphatidylethanolamine (PE) 
in mixed membranes, resulting in disruption of membrane integrity, was confirmed using NMR (Mason et al., 2006). Interestingly, the three His residues, which become protonated at acidic $\mathrm{pH}$, play no role in membrane disruption, most likely due to their position along the spine of the helix where they would be unlikely to interact with lipid head groups.

The Gly13 residue in the middle of pleurocidin confers flexibility between a longer $\alpha$-helix at the amino terminus and a shorter $\alpha$-helix at the carboxy terminus allowing it to interact with the negatively charged phospholipid membranes (Yang et al., 2006). Replacing Gly13 with Ala removes this hinge region, resulting in a much higher $\alpha$-helical content and loss of cell selectivity. This analog is hemolytic and interacts with both negatively charged (mimicking bacterial and cancer cell membranes) and zwitterionic (mimicking erythrocyte and normal mammalian cell membranes) phospholipids. Similarly, substitution of both Gly13 and Gly17 by Ala results in a large increase in $\alpha$-helicity and a correspondingly dramatic increase in hemolytic activity, indicating that the hinge region facilitates flexibility and confers bacterial cell selectivity (Lim et al., 2004a). It is interesting that Gly13 is conserved in 15 of the 26 identified pleurocidin variants whereas Gly17 is conserved in only 6, indicating that Gly13 plays the more important role in peptide function.

Sterols are commonly found in eukaryotic but not bacterial cell membranes, and their presence in anionic mixed membranes reduces the ability of pleurocidin to insert even though the peptide maintains its $\alpha$-helical configuration (Mason et al., 2007). Cholesterol, found in membranes of higher eukaryotes, was shown to be more effective than ergosterol, commonly found in those of fungi and certain protozoa, in reducing insertion of CAPs. These differences in membrane sterol content explain the differential sensitivity of bacteria, lower eukaryotes and higher eukaryotes to CAPs such as pleurocidin. Using a fluorescent membrane probe, pleurocidin has been shown to structurally perturb the plasma membrane of the fungal pathogen Candida albicans (Jung et al., 2007), confirming earlier killing assay results (Patrzykat et al., 2003).

Structural modelling predicted that only 12 of the 26 described pleurocidin variants formed amphipathic $\alpha$-helices and killing assays showed that these were cytotoxic to HL-60 human leukemia cells, resulting in rapid and complete killing (Morash et al., 2011). Cell death was non-apoptotic and probably occurred by the formation of ion channels that dissipated the membrane potential and led to cell lysis. The active pleurocidin variants were the more highly charged (>+6.5) members of the family; interestingly only one of them was also hemolytic. The anti-cancer activities of two pleurocidin variants (NRC-03 and NRC-07) against breast cancer cells involve binding to negatively charged cell-surface molecules (Hilchie et al., 2011).

\subsection{Intracellular effects}

A number of CAPs, when administered at low doses, are able to penetrate the bacterial membrane and disrupt metabolic processes (see Marcos and Gandia, 2009; Nicolas, 2009). CAPs can assume different structures whilst exerting their inhibitory effects. For example, when bound to DNA, buforin II assumes an extended form whereas magainin and pleurocidin assume an $\alpha$-helical form and bind DNA less effectively (Lan et al., 2010). Combinations 
of CAPs that exert their effects on different targets may exhibit synergy, and provide more potent killing activity.

Pleurocidin usually causes membrane disruption at high concentrations whereas at low concentrations, it can translocate into the cytoplasm without causing cell lysis and exert its effects intracellularly, inhibiting DNA, RNA and protein synthesis (Patrzykat et al., 2002). The intracellular effect of pleurocidin NRC-03 has since been probed using zebrafish embryos, and shown to target the mitochondria and generate superoxide (Morash et al., 2011). TUNEL staining indicates that the DNA of some cells becomes degraded, whereas other cells undergo rapid lysis and cell death without DNA fragmentation. Pleurocidin variants NRC-03 and NRC-07 cause mitochondrial membrane damage and production of reactive oxygen species (ROS) in MDA-MB-231 breast cancer cells (Hilchie et al., 2011).

\subsection{Receptors and binding proteins}

In most cases, killing is by nonreceptor-mediated mechanisms since all D-amino acid enantiomers are generally as active as the natural L-amino acid peptides. However, stereospecific receptor-mediated translocation has been described (Nicolas, 2009) and some CAPs transduce their effects via signaling networks upon interaction with receptors. Quite a diversity of receptors have been described, possibly reflecting the diversity in peptide structures. Uptake of apidaecin into Gram negative bacteria is proposed to by an energy-dependent mechanism involving a permease or transporter (Castle et al., 1999). The detection of peptide:receptor complexes is technically very difficult but some receptors have been identified. For example, the outer membrane protein OprI from P. aeruginosa (Lin et al., 2010) and the outer membrane lipoprotein Lpp in Enterobacteriaceae (Chang et al., 2012) have been shown to serve as receptors for $\alpha$-helical CAPs. Histatin 5 and some defensins bind Ssa1/2 proteins on the cell surface of $C$. albicans in order to exert their activity, and the potassium transporter TRK1 is also required for histatin5 fungicidal activity (Vylkova et al., 2007). In eukaryotic cells, formyl peptide receptor-like 1 (FPRL1) is used as a receptor for LL-37 to act as a chemoattractant (Yang et al., 2000) and induce angiogenesis (Koczulla et al., 2003). LL-37 has also been shown to mediate keratinocyte migration and cytokine release by transactivation of the epidermal growth factor receptor (Tokumaru et al., 2005) and P2X7 receptor (Elssner et al., 2004), respectively. However, activation of receptors could be via CAPinduced changes in membrane fluidity, ion transport and/or receptor aggregation (Braff et al., 2005) rather than direct binding.

Activation of mast cells by pleurocidin is G protein-dependent and proposed to involve FPRL1 and $G$ protein coupled receptor signaling pathway (Kulka, unpub). The observation that pleurocidin can bind and activate FPRL1 has some important implications for human disease. The FPRL1 receptor subtype is also a receptor for the bacterially-derived peptide fMLP (N-formyl-L-methionyl-L-leucyl-L-phenylalanine) making it an important innate immune receptor (Selvatici et al., 2006). FPRL1 activates key components of the innate immune system and is responsible for chemotactic responses, superoxide anion production and degranulation by neutrophils, macrophages and mast cells. FPRL function has been shown to be important in chronic obstructive pulmonary disease (COPD) due to cigarette smoking (Car- 
dini et al., 2012). FPRL1 can also transactivate epidermal growth factor receptors (EGFR) making them a potentially important target in lung cancer (Cattaneo et al., 2011).

\section{Biological activities and therapeutic applications of cationic antimicrobial peptides}

\subsection{Antibacterial}

Because of their rapid, broad spectrum bactericidal action, potency, and low host cytotoxicity, CAPs have elicited much excitement as alternatives to current antibiotics, particularly in the fight against antibiotic-resistant pathogens (Nijnik and Hancock, 2009). CAPs can cause bacterial cell death by disrupting the bacterial membrane, by entering the cell and inhibiting intracellular targets, or by stimulating the immune system to eliminate an infection. They can be used alone or together with other antibacterial agents, with which they frequently synergize.

Pleurocidins show broad-spectrum antimicrobial activity at micromolar concentrations and also show synergistic activity with several antibiotics (Cole et al., 2000; Douglas et al., 2003; Patrzykat et al., 2003). In contrast to many CAPs, pleurocidin is insensitive to $\mathrm{NaCl}$ concentrations up to $150 \mathrm{mM}$, and may therefore have application in relatively high-salt bodily fluids and in treatment of lung infections in patients with cystic fibrosis, who have even higher $\mathrm{NaCl}$ content (Goldman et al., 1997).

Recent studies have shown that pleurocidin possesses considerable activity against oral microorganisms growing both planktonically and as a biofilm, even in the presence of saliva (Tao et al., 2011). Incorporation of a targeting moiety to pleurocidin NRC-04 has significantly increased its specificity towards $S$. mutans, the main cause of dental caries, relative to other oral bacteria (Mai et al., 2011). Addition of 5 mM EDTA or 10 ppm sodium fluoride, two compounds commonly used in oral treatments, resulted in increased killing of S. mutans. Replacement of Ser14 by His improved the activity of the targeted peptide at low $\mathrm{pH}$ similar to that found in the oral cavity, showing that this targeted pleurocidin has good potential as an anticaries agent.

Foodborne infections, especially those of seafood are a major health problem, yet only one $\mathrm{CAP}$, nisin, has been approved by the FDA for use as a food preservative and it has only limited activity against Gram-negative bacteria or fungi (Burrowes et al., 2004).

Pleurocidin was tested against Gram-positive and Gram-negative bacteria of interest in food safety and shown to be highly effective against 17 of 18 strains, particularly the fish spoilage bacterium Vibrio alginolyticus (Burrowes et al., 2004). In addition, it was active against the yeasts S. cerevisiae and P. pastoris, and the mold P. expansum, but was not detrimental to human red blood cells or intestinal epithelial cells, indicating that it would be safe to use as a food preservative. Furthermore, since pleurocidin is produced naturally by an edible fish, there are fewer concerns over its use in food preservation. 


\subsection{Antifungal}

The antifungal properties of CAPs have been recognized for some time (De Lucca and Walsh, 1999); however, it is only recently that the mechanism of action has been elucidated. While some CAPs such as LL-37 kill fungal cells by lysing the cell membrane, others such as histatin and defensins 2 and 3 kill in an energy-dependent and salt-sensitive fashion without cell lysis (den Hertog et al., 2005; Vylkova et al., 2007). Magainin 2 and dermaseptin S3(1-16) also cross the cell membrane and interfere with DNA integrity (Morton et al., 2007a; Morton et al., 2007b). Histatin 5, lactoferrin, arenicin-1 and several other CAPs inhibit mitochondrial respiration and induce the formation of ROS and subsequent apoptosis in C. albicans (Andres et al., 2008; Cho and Lee, 2011b; Helmerhorst et al., 2001; Hwang et al., 2011a; Hwang et al., 2011b).

Attempts to improve antifungal activity of CAPs have resulted in structural analogs with increased selectivity towards fungi and less host cytotoxicity. Hydrophobicity was shown to be a crucial factor in the antifungal activity of a series of CAP analogs against zygomycetes vs ascomycetes (Jiang et al., 2008). Synthetic, non-peptidic analogs of naturally-occurring CAPs have shown potent activity as anti-Candida agents against biofilms in the oral cavity, and reduced mammalian cytotoxicity (Hua et al., 2010).

Pleurocidin also possesses activity against C. albicans (Cole et al., 2000; Douglas et al., 2003; Patrzykat et al., 2003) and various derivatives truncated at the amino or carboxy-termini show reduced hemolytic activity although they are generally less potent (Lee and Lee, 2010). Modification of pleurocidin to decrease hydrophobicity and $\alpha$-helicity also resulted in active peptides with reduced hemolytic activity (Sung and Lee, 2008). A synthetic all-D amino acid entantiomer of pleurocidin has also been designed that showed resistance to trypsin, plasmin and carboxypeptidase B proteases in vitro with no loss in antifungal activity (Jung et al., 2007). Pleurocidin induces ROS, oxidative stress, mitochondrial depolarization, caspase activation, and apoptosis in C. albicans with concomitant membrane phosphatidylserine externalization, cell shrinkage, DNA fragmentation and nuclear condensation (Cho and Lee, 2011a).

\subsection{Antiviral}

Enveloped viruses are often susceptible to attack by CAPs. Four different linear CAPs were shown to inactivate vaccinia virus by removal of the outer membrane, thereby rendering the inner membrane susceptible to neutralizing antibody against the exposed antigens (Dean et al., 2010). Novel HIV-1-inhibitory peptides have recently been identified by screening the APD Antimicrobial Peptide Database for CAPs with promising antiviral properties. This uncovered 30 candidate CAPs which, when synthesized and tested, resulted in 11 peptides with $\mathrm{EC}_{50}<10 \mu \mathrm{M}$ against HIV-1 (Wang et al., 2010). Some CAPs are able to exert antiviral effects by blocking cell surface receptors used for viral entry. For example, the polyphemusin analog T22 binds CXCR4 on T cells and prevents T cell line-tropic HIV-1 entry (Murakami et al., 1997).

The antiviral activity of pleurocidin variants has been tested against vaccinia virus grown in HeLa cells and four lead candidates were identified based on viral inhibition without HeLa cytotoxicity at both high and low multiplicity of infection (MOI) (Johnston, pers. comm.). At 
the more biologically relevant low MOI, two peptides were inhibitory with an $\mathrm{IC}_{50}<1 \mu \mathrm{g} / \mathrm{ml}$. Further studies are required to determine the mechanism by which pleurocidin exerts its antiviral effect.

\subsection{Anti-parasitic}

The anti-parasitic properties of magainins and cecropins have been known for over twenty years and have subsequently been reported for many other CAPs (Harrington, 2011; Mor, 2009). CAPs are able to traverse the membranes of parasite-infected erythrocytes and are proposed to change the properties of the parasite cell membrane, cause membrane lysis, or become internalized and interfere with biological processes. BMAP-28, BMAP-27 and the less cytotoxic truncated derivative BMAP-18 have recently been shown to possess excellent in vitro activity against Leishmania and African trypanosomes growing both in mammalian cells and in cells of the insect vector (Haines et al., 2009; Lynn et al., 2011). Importantly, BMAP-18 was also able to inhibit release of leukocyte LPS-induced TNF- $\alpha$ associated with inflammation and cachexia in patients with sleeping sickness. Further in vivo studies of naturally-occurring and engineered CAPs are needed to demonstrate their potential in the treatment of serious parasite diseases of humans.

Pleurocidin inhibited the bloodstream form of Trypanosoma brucei at low concentration but was not effective against the procyclic culture form or the tsetse symbiont (Haines et al., 2003).

\subsection{Anticancer}

In contrast to conventional chemotherapy drugs that target all actively proliferating cells, CAPs can show selective cytotoxicity towards cancer cells including dormant, slow-growing, and multidrug resistant cells (see Hoskin and Ramamoorthy, 2008)). Both apoptotic (Jin et al., 2010) and non-apoptotic (Ceron et al., 2010; Hilchie et al., 2011; Morash et al., 2011) mechanisms have been proposed. The $\alpha$-helical CAP, temporin-1CEa, exhibits cytotoxicity towards all of 12 tested human carcinoma cell lines in a concentration-dependent manner, yet no significant cytotoxicity to normal human umbilical vein smooth muscle cells at concentrations that showed potent antitumor activity (Wang et al., 2011). The basis for selectivity is thought to be the presence of phosphatidylserine, which is exposed on non-apoptotic tumor cells including malignant metastatic cells and primary cell cultures. Susceptibility of metastatic cells suggests that CAPs may be useful in treating metastatic as well as primary cancers (Riedl et al., 2011).

In addition to direct killing of cancer cells, CAPs can affect T-cell dependent tumor regulation. Recently, intratumoral administration of a lactoferricin derivative into lymphomas established in mice resulted in tumor necrosis, infiltration of inflammatory cells, and regression of tumors. Transfer of spleen cells from treated mice provided long-term, specific $\mathrm{T}$ cell-dependent immunity against the lymphoma, suggesting therapeutic vaccination against cancer using CAPs may be possible (Berge et al., 2010). In contrast, LL-37 was able to 
induce apoptosis of $\mathrm{T}$ regulatory cells, thus inhibiting their immune suppressor activity and thereby enhancing the anti-tumor response (Mader et al., 2011).

Pleurocidins selectively killed human leukemia cells at low concentrations ( $<32 \mu \mathrm{g} / \mathrm{mL}$ ) (Morash et al., 2011) as well as multiple breast cancer cell lines (Hilchie et al., 2011) by a predominantly membranolytic mechanism. Disruption of the cell membrane also augmented the activity of the chemotherapeutic cisplatin, presumably by enhancing access to the nucleus. Furthermore, when administered intratumorally into breast cancer xenografts in mice, pleurocidin inhibited tumor growth and induced tumor necrosis, while not causing observable adverse effects on the mice (Hilchie et al., 2011). These advantageous properties indicate that pleurocidins should be pursued as novel anticancer agents.

\subsection{Immunomodulatory}

CAPs show multiple activities associated with modulation of the immune system (Jenssen and Hancock, 2010; Yeung et al., 2011) and have been postulated to represent an evolutionary link bridging innate and adaptive immune responses (Selsted and Ouellette, 2005). CAPs are directly chemotactic for immune cells and also stimulate chemokine and cytokine secretion (Lai and Gallo, 2009). Some CAPs are able to boost protein antigens and vaccines that have low immunogenicity by inducing proinflammatory cytokines such as TNF, IFN and IL-1 $\beta$ (Kindrachuk et al., 2009; Mutwiri et al., 2007; Tavano et al., 2011), suggesting that they would be good adjuvants (Huang et al., 2011; Li et al., 2008). CAPs play a critical role in wound healing (Steinstraesser et al., 2008), promoting keratinocyte migration (Aung et al., 2011a), re-epithelialization (Hirsch et al., 2009), deposition of extracellular matrix (Oono et al., 2002), and angiogenesis (Koczulla et al., 2003). Human $\beta$-defensins and LL-37 are able to stimulate mast cells, and recently the neuroendocrine CAP catestatin has been reported to induce migration and degranulation of mast cells, release of lipid mediators and production of cytokines and chemokines (Aung et al., 2011b). CAPs also show promise in counteracting sepsis, a major cause of morbidity and mortality in hospitalized patients. For example, intraperitoneal injection of LPS-sensitized mice with S-thanatin reduced serum endotoxin and TNF- $\alpha$ levels, resulting in 100\% survival (Wu et al., 2011).

Pleurocidin has a proinflammatory effect in fish cells in vitro, inducing expression of IL-1 $\beta$ and COX-2 (Chiou et al., 2006). In addition, pleurocidin variant NRC-08, which has no antibacterial activity, induced the expression of the co-stimulatory marker CD40 as well as IL-12p40, TNF, and TGF from mouse bone marrow-derived immature dendritic cells (Phillips, Lee \& Douglas, pers. comm.). The potential immunomodulating effects of this particular pleurocidin variant, which promotes the maturation of DCs, suggest that it could be further explored as a candidate adjuvant for a Th1 response to vaccine antigens.

Pleurocidins activate human mast cells to release granule contents such as histamine and proteases (Kulka, per. comm.) both of which are important in allergic inflammation and tissue hometostasis. Mast cells are critical regulators of the tissue microenvironment capable of responding to many different stimuli including allergens and releasing a huge variety of pro-inflammatory and immunomodulatory mediators. Interestingly, pleurocidin activation of mast cells is unique from that of allergens. Allergens bind to and crosslink surface high 
affinity immunoglobulin E receptors (FceRI), which activates increases in intracellular calcium and initiates several signaling pathways. Whereas FceRI activation results in degranulation, arachidonic acid metabolite release and pro-inflammatory mediator production, pleurocidin activation of FPRL1 initiates degranulation and production of relatively small amounts of chemokines. Furthermore, whereas FceRI engagement does not activate mast cell chemotaxis, pleurocidins modify adhesion via the fibronectin receptor (CD29) and promote mast cell migration. This suggests that pleurocidins activate selective signaling pathways in mast cells and may be useful tools in targeted mast cell-dependent therapy.

\subsection{Cytotoxic}

\subsubsection{Hemolysis and host cell lysis}

Although most CAPs are not hemolytic or cytolytic at the concentrations used for killing microbes or cancer cells, some do exhibit that characteristic, melittin being the most notorious (Tosteson et al., 1985). Magainin also forms pores in human cell membranes and enters the cell within minutes, accumulating in the nucleus and mitochondrion (Imura et al., 2008). Bovine myeloid antimicrobial peptides BMAP-27 and BMAP-28 at 10 times minimal inhibitory concentration (MIC) are toxic towards human erythrocytes and polymorphonuclear cells and induce apoptosis in transformed cell lines and in vitro-activated lymphocytes at concentrations near MIC (Risso et al., 1998). A recent high-throughput method to assess cytotoxicity of melittin and structural variants differing in hydrophobicity, amphipathicity and helicity, showed it to be more sensitive than standard tests such as erythrocyte lysis and MTT assay and holds promise for identifying CAP variants with non-hemolytic properties (Walsh et al., 2011).

Hemolysis assays of 26 variants of pleurocidin showed that only one, a histidine-rich variant NRC-19, showed any ability to lyse red blood cells up to a concentration of $128 \mu \mathrm{g} / \mathrm{mL}$, well above the concentrations required to kill bacterial and cancer cells (Morash et al., 2011). The selectivity of these peptides indicates that they would be excellent candidates as antibacterial and anti-cancer agents.

\subsubsection{Sepsis}

While many CAPs can reduce sepsis, some actually exacerbate the problem. This is because they are so effective at killing bacterial cells that they cause the release of endotoxin from lysed cells, eliciting an excessive inflammatory response (Risso et al., 1998; Steinstraesser et al., 2003).

Preliminary studies using a mouse cytokine array showed that pleurocidin variants NRC-03 and NRC-08 are able to repress LPS-induced TNF- $\alpha$ and IL-10 secretion from mouse RAW264.7 macrophages, indicating that they may be considered for the control of sepsis (Carroll, Patrzykat \& Douglas, pers. comm.). 


\section{Isolation and discovery of cationic antimicrobial peptides}

\subsection{Traditional biochemical purification}

Standard biochemical techniques for isolation of small peptides have been used to isolate CAPs from tissues, skin secretions and other biological fluids. Briefly, tissue lysates or fluids are diluted in $0.1 \%$ trifluoroacetic acid (TFA) and extracted under ice-cold acid conditions. After centrifugation, the acidic supernatant is loaded on a C18 column and the peptide eluted with increasing acetonitrile (5-80\%) in $0.05 \%$ TFA. Those fractions with antimicrobial activity are pooled and further purified by reverse-phase HPLC with increasing acetonitrile $(5-55 \%)$ in $0.05 \%$ TFA. The material in absorbance peaks is then pooled, dried under vacuum and reconstituted in MilliQ water for mass and sequence analysis using mass spectrometry and automated Edman degradation.

Pleurocidin was originally isolated from homogenates of the skin and mucus secretions of winter flounder using C18 chromatography followed by size fractionation on Sephadex G-50 (Cole et al., 1997). Biologically active fractions were pooled and subjected to strong cation exchange HPLC and then reversed phase HPLC.

\subsection{Genomics approaches to antimicrobial peptide discovery}

Once even a partial amino acid sequence of a CAP is known, genomic strategies can be employed to identify and isolate DNA sequences encoding CAPs. This can involve screening of cDNA and genomic libraries using oligonucleotide probes or amplification of CAP-encoding sequences from genomic or cDNA by PCR (Iwamuro and Kobayashi, 2010). CAP-encoding sequences can also be identified in genomic and EST sequencing databases by similarity searching using bioinformatics search engines such as BLAST (Browne et al., 2011; Fernandes et al., 2010). Full-length cDNA sequences can then be obtained by 5 '- and $3^{\prime}$-RACE. The identification of 28 new human and 43 new mouse $\beta$-defensin genes was achieved using a computational search tool to find conserved motifs in draft genome sequences (Schutte et al., 2002).

Pleurocidin was originally cloned from cDNA and genomic libraries using degenerate oligonucleotide probes (Cole et al., 2000; Douglas et al., 2001) or PCR amplicons encoding individual pleurocidin variants (Douglas et al., 2003). Additional pleurocidin variants were amplified by PCR from cDNA of different flatfish species using primers corresponding to the conserved amino-terminal signal peptide and carboxy-terminal anionic propiece (Patrzykat et al., 2003). At least 30 variants have now been cloned (Figure 3).

\subsection{In silico discovery and rational peptide design}

Various in silico methods have been used to rationally design CAPs and predict their biological activity (Hadley and Hancock, 2010). These include the use of artificial neural networks, support vector machines and quantitative structure activity relationship (QSAR) modeling (Fjell et al., 2011; Torrent et al., 2011). Combinatorial synthesis and high throughput peptide synthesis using SPOT technology (Hilpert et al., 2007) together with a QSAR-based artificial 
neural network system (Fjell et al., 2009) have also been used to design active synthetic CAPs. This approach, coupled with high-throughput screening assays using peptide arrays, is invaluable for inexpensively generating large numbers of potential candidates for clinical assessment (Cherkasov et al., 2009).

\section{Production of cationic antimicrobial peptides}

\subsection{Peptide synthesis}

Isolation of CAPs from the native producer is not feasible on the scale necessary for investigating therapeutic value and pharmaceutical potential. Therefore, CAPs are usually synthesized by standard solid-phase methods using 9-fluorenyl-methoxycarbonyl (F-moc) protecting groups, cleaved from the resin with $95 \%$ trifluoroacetic acid, purified by reversephase high performance liquid chromatography using an acetonitrile gradient, and the mass is verified by mass spectrometry. Although synthesis of linear $\alpha$-helical peptides is fairly routine, good yields of CAPs that require cysteine oxidation to form the correct disulphide bonding pattern are rarely obtained (Tay et al., 2011). Modifications such as carboxy-terminal amidation, biotinylation, fluorescent labeling, incorporation of D-amino acids, acylation, etc. are available for synthetic peptides.

\subsection{Fermentation}

\subsubsection{Bacteria}

Production of CAPs in bacteria using recombinant technology, by definition, is a challenge as they inhibit or kill the host bacteria and bacterial proteases can degrade them. Recombinant technology, particularly of tagged fusion peptides, has been used successfully to produce high yields of pure CAP at relatively low cost (Ingham and Moore, 2007). Factors to be considered include optimization of promoter sequence and codon usage from the source organism to bacterial host, signal peptide, tag, fusion partner, ease and cost of cleavage, and cost of subsequent purification steps. A recent approach involving secretion of the tagged SUMO-CAP hybrid into the medium followed by removal of the mature CAP by sumoase protease has been particularly successful in large-scale production of several CAPs (Bommarius et al., 2010; Li et al., 2009). In general, production of $\alpha$-helical CAPs without disulfide bonds and easily cleavable from their fusion partner has proved to be the most straightforward and cost-effective. A recent report of expression of human $\beta$-defensin 28 in E. coli is encouraging, however (Tay et al., 2011). By using a construct with both a His-tag and maltose binding protein and including the site for cleavage by $\mathrm{TeV}$, an inexpensive and efficient protease for releasing the mature $\mathrm{CAP}$, large-scale production of correctly folded defensin was achieved.

Pleurocidin has been successfully expressed as a PurF fusion peptide in inclusion bodies, generating milligram quantities of pure peptide (Bryksa et al., 2006). By incorporating 
$\left({ }^{15} \mathrm{NH}_{4}\right)_{2}-\mathrm{SO}_{4}$ as the sole nitrogen source in the growth medium, structural elucidation of the uniformly ${ }^{15} \mathrm{~N}$-labelled peptide by NMR was greatly facilitated (Syvitski et al., 2005).

\subsubsection{Fungi}

Fungi such as Saccharomyces cerevisiae and Pichia pastoris represent alternative systems for recombinant expression of CAPs. P. pastoris is a methylotrophic yeast that is capable of producing 10-100 times more recombinant protein than $S$. cerevisiae. However, successful production of small proteins less than $10 \mathrm{kDa}$ in $P$. pastoris can be problematic due to low expression, RNA instability or translational blocks. Low amounts $(\sim 1 \mathrm{mg} / 100 \mathrm{~mL})$ of recombinant cecropin were produced in P. pastoris (Jin et al., 2006), and recently, high-level production $(>200 \mathrm{mg} / \mathrm{L})$ of active recombinant hPAB- $\beta$ (Chen et al., 2011) and plectasin (Zhang et al., 2011) was achieved in this system.

Production of pleurocidin was attempted using this system; however, no recombinant peptide was recovered, despite correct integration of the pleurocidin sequence into the yeast genome and normal transcription (Burrowes et al., 2005).

\subsubsection{Animal cells}

Production of CAPs in animal cells has the advantage of accurate processing of the recombinant peptide and addition of post-translational modifications. However, there are few reports of CAP production using this approach. The insect cell/baculovirus system has been used to produce recombinant human $\beta$-defensins (Feng et al., 2005) and biologically active hepcidin was successfully expressed, processed and secreted in human embryonic kidney cells (Wallace et al., 2006). The complete pleurocidin pre-pro-peptide gene was cloned into a carp cell line under the control of the carp $\beta$-actin promoter. The precursor peptide was expressed continuously for over two years and the mature peptide was secreted into the medium (Brocal et al., 2006).

\subsection{Transgenic organisms}

Early attempts were made to express CAPs in the milk of transgenic mice (Yarus et al., 1996), tissues of catfish (Dunham et al., 2002), and leaves of tobacco (Yevtushenko et al., 2005) and rice (Imamura et al., 2010); however, while the recombinant CAPs were able to confer pathogen resistance to the host organism, these systems are not designed for largescale production of CAPs for human applications.

\section{Modifications to enhance biological activity and stability}

\subsection{Amino acid substitutions, additions and deletions}

Modification of the amino acid sequence of CAPs to change the charge, hydrophobicity and bulkiness can have dramatic effects on their ability to interact with membranes and exert 
their biological activity. Amidation of the carboxy terminus usually results in enhanced activity by increasing the net positive charge but has a negligible effect on protease susceptibility. On the other hand, N-terminal acetylation significantly increases resistance to aminopeptidases but decreases antimicrobial activity (Nguyen et al., 2010). In general, high hydrophobicity confers hemolytic and cytotoxic properties on CAPs (McPhee and Hancock, 2005). The effect of amino acid substitutions on antimicrobial vs hemolytic activity has been comprehensively evaluated using a series of rationally designed CAPs of 20 amino acids that differ in charge, polar angle, hydrophobicity and hydrophobic moment (Chou et al., 2008). Increasing the His content of clavanin resulted in an acid-activated CAP that showed enhanced activity against the caries-producing pathogen, S. mutans, at low $\mathrm{pH}$ ( $\mathrm{Li}$ et al., 2010). Substitution of Lys by His in a 15-mer CAP resulted in a peptide that was cationic only in the acidic microenvironment found in tumors, and exhibited enhanced anti-tumor activity and reduced systemic toxicity (Makovitzki et al., 2009). Addition of hydrophobic amino acids to the termini of CAPs can also increase potency, although reduced solubility and increased production cost present important drawbacks (Hadley and Hancock, 2010). Recent reports of a truncated frog gaegurin (Won et al., 2011b) and the naturally short bee anoplin (Won et al., 2011a) CAPs emphasize the enhanced antimicrobial effects of such modifications on bacteria and model membranes.

Naturally occurring pleurocidins have variable amino acid sequences that confer different activities against microbes and cancer cells (Morash et al., 2011; Patrzykat et al., 2003). Alignment of the amino acid sequences of the mature peptides revealed conserved positions that could be of importance in bioactivity. For example, the highly conserved Gly13 residue in the middle hinge region is important for $\alpha$-helicity (Lim et al., 2004b) and the hydrophobic amino acids in the N-terminal region are more crucial for antifungal activity than those in the C-terminal region (Lee and Lee, 2010). Replacement of Ser14 by His improved the activity of a targeted pleurocidin towards S. mutans at low $\mathrm{pH}$, which is often found in the oral cavity (Mai et al., 2011).

\subsection{Non-natural amino acids and enantiomers}

Replacement of L-amino acids by their D counterparts generally does not diminish biological activity but does confer protease resistance on the peptide (Lee and Lee, 2008; Park et al., 2010). Retro-inversion, in which amino acid stereochemistry is changed as well as peptide bond direction yielding isomers with similar side chain topology to the native peptide, has generally met with limited success although partially modified retro-inverso peptides show more promise (Fischer, 2003). Incorporation of non-natural amino acid analogs (Knappe et al., 2010; Marsh et al., 2009) is also effective. Recently, a series of CAPs containing Tic-Oic dipeptide analogues was developed to combat 11 potential bio-terrorism and drug-resistant strains of bacteria (Venugopal, 2010). These CAPs were metabolically stable, potent, and showed selectivity for bacterial relative to host cell membranes.

Replacement of L-Lys and L-Arg residues with D-Lys and D-Arg in pleurocidin conferred resistance to digestion by trypsin but also abolished activity, presumably because the $\alpha$-helical structure was disrupted by the inclusion of just a subset of amino acids (Douglas, un- 
pub.). In support of this, an all D-amino acid analog of pleurocidin showed proteolytic resistance and double the antifungal (Jung et al., 2007) and antibacterial (Lee and Lee, 2008) potency. Similarly, an all D-amino acid analog of pleurocidin NRC-03, showed improved activity against breast cancer cells compared to the natural L-form peptide (Hilchie, Hoskin, unpub).

\subsection{Peptidomimetics}

Peptidomimetics such as $\beta$-peptides and peptoids have been designed that maintain the amphiphilic structure and antimicrobial activity and are resistant to protease degradation; these abiotic structures exhibit in vivo stability and enhanced bioavailability (Rotem and Mor, 2009; Scott et al., 2008). Synthetic mimics of antimicrobial peptides (SMAMPs) that adopt amphiphilic secondary structures and possess potent and selective antimicrobial activity have been inexpensively synthesized from small synthetic oligomers (Lienkamp et al., 2008; Scott et al., 2008). Another novel technique is hydrocarbon stapling (Sa'adedin and Bradshaw, 2010) in which an $\alpha$-helical peptide is chemically modified to generate a relatively protease resistant, cell-permeable peptide that binds its target with increased binding affinity.

\subsection{Acylation}

Addition of fatty acid chains to the termini of CAPs can increase their antibacterial activity or endow them with antifungal activity. Linear oligomers consisting of alternating uncharged and cationic Lys residues displayed varying degrees of antibacterial, antifungal and hemolytic activity when they were N-acylated, depending on the length of the acyl group and the different degrees of oligomerization that were induced (Shai et al., 2006). Addition of fatty acids of increasing lengths to magainin increased the extent of oligomerization of the resulting lipopeptide, and concurrently the antifungal activity.

\subsection{Cyclisation}

Cyclisation by, for example, disulfide bridge formation or head-to-tail backbone cyclization, results in a more constrained peptide structure that is less susceptible to protease degradation (Nguyen et al., 2010). Cyclisation of two cationic hexapeptides, including the active portion of lactoferricin, was found to be highly effective for both serum stability and antimicrobial activity. Interestingly, disulfide cyclization resulted in more active peptides while backbone cyclization resulted in more proteolytically stable peptides. The modifications did not result in hemolytic activity, thereby making them attractive therapeutic candidates. Dendrimers of CAPs have enhanced ability to permeabilize membranes and are stabler than monomeric forms (Pieters et al., 2009).

\subsection{Targeted and hybrid peptides}

One of the drawbacks of antibiotic use is the deleterious effect broad spectrum antibiotics have on the normal microflora, which often allows opportunistic pathogens such as C. albicans and $S$. aureus to overgrow after treatment. Selectively targeted antimicrobial peptides (STAMPs) can overcome this problem and can selectively kill the target species while leav- 
ing the benign commensals largely unaffected. This effect was first demonstrated using a STAMP consisting of a competence stimulating peptide (CSP) moiety targeting the cariescausing pathogen Streptococcus mutans attached to a killing moiety derived from novispirin G10 (Eckert et al., 2006). Incorporation of such a STAMP into an oral rinse resulted in reduction in salivary S. mutans, plaque, lactic acid and enamel demineralization, suggesting further clinical evaluation is warranted (Sullivan et al., 2011). Targeting of tumor cells has also been achieved and addition of the tumor-homing peptide bombesin to the amino terminus of magainin 2 resulted in tenfold enhanced killing in vitro and decrease in the size of tumor xenografts in mice (Liu et al., 2011).

We have used this approach to combine the minimal targeting portion of CSP with the killing domain of pleurocidin variant NRC-04 to treat S. mutans in both planktonic and biofilm conditions. The hybrid peptide was selectively active against $S$. mutans in the presence of saliva and physiological or higher salt concentration and was non-hemolytic (Mai et al., 2011). Furthermore, activity was augmented by a preventative dose of $1 \mathrm{mM} \mathrm{NaF}$, a compound commonly used in oral care. The development of such targeted peptides paves the way for their use as a probiotic treatment to prevent dental caries.

\section{Advantages and limitations of cationic antimicrobial peptides}

\subsection{Bioactivity}

CAPs exert rapid, broad spectrum, bactericidal activity at micromolar concentrations and are valuable weapons in the fight against antibiotic-resistant microbes e.g. MRSA. In addition, targeted CAPs may be used as probiotics to eradicate pathogenic bacteria while leaving normal flora unaffected. Their ability to kill fungi, viruses and parasites is also beneficial clinically. Many CAPs neutralize endotoxin and can be used to counteract sepsis or to enhance host defenses through immunomodulatory effects. Increased innate clearance of microbes results in less bacterial debris (van der Does et al., 2010) and ensuing inflammation (Andra et al., 2006). Their application both in killing tumor cells and in enhancing host antitumor responses is gaining momentum (Yeung et al., 2011).

\subsection{Resistance}

CAPs have a low propensity to induce microbial resistance, mainly due to their multiple targets and mechanisms of action. CAPs are usually expressed in high concentrations only at sites of infection; continuous exposure of microbes, which often leads to resistance, is therefore minimized. In addition, cocktails of several different CAPs are often produced simultaneously, leading to increased microbial killing.

Despite this, some reports on the emergence of resistance have appeared. These include reduction in bacterial cell surface negative charge, secretion of exoproteases and induction of transporters (see Nizet, 2006; Peschel and Sahl, 2006), all of which require significant expen- 
diture of metabolic energy by the microbe. In most cases, the resistance that arises is very low compared to conventional antibiotics.

In Gram negative organisms such as Salmonella and Pseudomonas, the PhoP-PhoQ two component sensor system has been shown to control resistance to aminoglycosides, polymyxin B, and cationic antimicrobial peptides (Macfarlane et al., 1999; Macfarlane et al., 2000; Groisman, 2001). In Pseudomonas, CAPs and the polymyxins are capable of inducing the pmrA-pmr genes and the putative LPS modification operon, thus increasing resistance to these agents (McPhee et al., 2003). The homologous basR-basS system of E. coli is also induced by exposure to sublethal concentrations of the proline-rich CAP, Bac7(1-35), suggesting that it may also mediate resistance (Tomasinsig et al., 2004). Resistance to Gram positive organisms such as Staphylococcus is mediated by the Aps three component sensor system, and interestingly, some CAPs are inducers of this system (Li et al., 2007). Recently, additional resistance genes in other bacteria such as Clostridium difficile (McBride and Sonenshein, 2011) and Vibrio (Shen et al., 2010) have been discovered, emphasizing the importance of this phenomenon.

\subsection{Cost}

Solid phase peptide synthesis is expensive and companies seeking regulatory approval for peptides in their pipelines require suppliers that adhere to good manufacturing practice (GMP) regulations, which also adds to the cost. However, there have been many advances in synthetic chemistry that have significantly reduced the cost of not only peptides but also non-peptide mimics and peptoids, and the lower operating costs of suppliers in Asia has resulted in more affordable peptides (Eckert, 2011).

\subsection{Stability}

Although CAPs represent a promising class of therapeutics, they have several in vivo drawbacks such as salt inactivation, protease degradation, and poor bioavailability. As described above, a number of approaches can be used to mitigate these limitations. Serum stability can be overcome by cyclisation or incorporation of amino acid analogs and some CAPs, particularly those such as pleurocidin that originated from marine sources, are active at physiological salt concentrations (Mai et al., 2011; Patrzykat et al., 2003).

\subsection{Side effects}

Some CAPs exhibit in vivo toxicity and for others there are unknown toxicity profiles (see section 5.7). Nephrotoxicity has been associated with polymixin cyclic peptides (Mogi and Kita, 2009). Since some CAPs can stimulate growth factor receptors, induction of tumorigenesis must be considered. Similarly, excessive release of histamine from mast cells must be avoided to minimize adverse reactions. 


\section{Clinical use and commercialization}

\subsection{Companies}

A number of CAPs and synthetic CAP analogs such as pexiganan ${ }^{\mathrm{TM}}$ (magainin derivative), omiganan $^{\mathrm{TM}}$ (indolicidin derivative), novispirin ${ }^{\mathrm{TM}}$ (cathelicidin derivative) and iseganan ${ }^{\mathrm{TM}}$ (protegrin-1 derivative) are now in commercial development. Several recent reviews describe the companies, their products and their progression through clinical trials (Eckert, 2011; Kindrachuk and Napper, 2010; Yeung et al., 2011; Zhang and Falla, 2010). Some candidates show great promise in the treatment of such disorders as HIV-associated oral candidiasis, acne, wound infections, diabetic foot ulcers, and oral biofilms. However, the inability to demonstrate advantage over existing therapeutics has resulted in failure of a number of CAPs at Phase III clinical trials. As appropriate formulations, bioassays and endpoints are established, the probability that these promising products will receive regulatory approval will improve.

\subsection{Formulations}

Because of systemic toxicity and bioavailability issues as well as the diverse and complex mechanisms of action, the majority of CAPs have been developed as topical formulations e.g. for diabetic foot ulcers (Lipsky et al., 2008) and skin infections (Falla and Zhang, 2010 ). Depending on the application, a number of different ways of formulating CAPs can be envisioned (Eckert, 2011). CAPs have been incorporated into lens preservation and artificial tear solutions (Huang et al., 2005) and aerosols (Lange et al., 2001). Inclusion of CAPs in coatings (Kazemzadeh-Narbat et al., 2010), polymers (Gao et al., 2011), hydrogels (Roy and Das, 2008), liposomes (Lange et al., 2001), micro- and nanoparticles (Bi et al., 2011; Garlapati et al., 2011) and even chewing gum (Faraj et al., 2007) also represent promising formulations. Long-term activity has been achieved by covalent immobilization of gramicidin A on functionalized gold surfaces and resulted in inhibition of Gram-positive and Gram-negative bacteria and the yeast Candida albicans for up to 6 months as well as delayed development of bacterial biofilm for 24 hours (Yala et al., 2011). Surface modifications by CAPs will be important in preventing colonization of medical devices such as catheters and bioimplants.

CAPs can also be used in combination therapies with each other or with approved antibiotics. For example, cecropin B enhanced the activities of beta lactams in rat septic shock models (Ghiselli et al., 2004). Cecropin A and magainin 2 administered together showed in vitro synergy against S. aureus in a mouse sepsis model (Cirioni et al., 2006). Magainin 2 administered with vancomycin showed the highest efficacy in this model.

Pleurocidin showed synergistic activity with inducible histone peptides and lysozyme in a salmonid in vivo infection model (Patrzykat et al., 2001). Studies with S. mutans showed that the efficacy of a targeted pleurocidin was increased in the presence of EDTA and sodium fluoride, two commonly used components of oral rinses (Mai et al., 2011). 


\subsection{Targeted delivery}

CAPs with cell-penetrating properties are under development as vectors for translocation of bioactive cargos with inherently poor membrane-crossing abilities into eukaryotic cells (Splith and Neundorf, 2011). Delivery of CAP-modified liposomes containing therapeutics to bacteria has also been reported, e. g. bacteria-targeted delivery of photodynamic antimicrobial chemotherapy to improve efficiency against MRSA and P. aeruguinosa in local infections (Yang et al., 2011).

\section{Conclusions}

CAPs show exciting promise as novel therapeutic agents, particularly in the fight against antibiotic-resistant bacteria and cancer and as immunostimulants. However, translation to clinical use has been hampered by concerns over stability, cost, systemic administration, known toxicity, and unknown long-term toxicity. The applications that show the most promise are those involving topical applications, particularly in combination with established antibiotics. Deeper understanding of the varied mechanisms of action of these diverse peptides and the production of cost-effective, stable, and highly selective CAPs will aid in bringing these molecules closer to the clinic.

\section{Author details}

Susan Douglas

Address all correspondence to: susan.douglas@nrc.ca

Institute for Marine Biosciences, Canada

\section{References}

[1] Aberg, K. M., Radek, K. A., Choi, E. H., Kim, D. K., Demerjian, M., Hupe, M., Kerbleski, J., Gallo, R. L., Ganz, T., Mauro, T., et al. (2007). Psychological stress downregulates epidermal antimicrobial peptide expression and increases severity of cutaneous infections in mice. J Clin Invest, 117, 3339-3349.

[2] Andra, J., Gutsmann, T., Garidel, P., \& Brandenburg, K. (2006). Mechanisms of endotoxin neutralization by synthetic cationic compounds. J Endotoxin Res, 12, 261-277.

[3] Andres, M. T., Viejo-Diaz, M., \& Fierro, J. F. (2008). Human lactoferrin induces apoptosis-like cell death in Candida albicans: critical role of $\mathrm{K}+$-channel-mediated $\mathrm{K}+\mathrm{ef}-$ flux. Antimicrob Ag Chemother, 52, 4081-4088. 
[4] Aung, G., Niyonsaba, F., Ushio, H., Hoq, M. I., Ikeda, S., Ogawa, H., \& Okumura, K. (2011a). A neuroendocrine antimicrobial peptide, catestatin, stimulates interleukin-8 production from human keratinocytes via activation of mitogen-activated protein kinases. J Dermatol Sci, 61, 142-144.

[5] Aung, G., Niyonsaba, F., Ushio, H., Kajiwara, N., Saito, H., Ikeda, S., Ogawa, H., \& Okumura, K. (2011b). Catestatin, a neuroendocrine antimicrobial peptide, induces human mast cell migration, degranulation and production of cytokines and chemokines. Immunology, 132, 527-539.

[6] Berge, G., Eliassen, L. T., Camilio, K. A., Bartnes, K., Sveinbjornsson, B., \& Rekdal, O. (2010). Therapeutic vaccination against a murine lymphoma by intratumoral injection of a cationic anticancer peptide. Cancer Immunol Immunother, 59, 1285-1294.

[7] Bi, L., Yang, L., Narsimhan, G., Bhunia, A. K., \& Yao, Y. (2011). Designing carbohydrate nanoparticles for prolonged efficacy of antimicrobial peptide. J Control Release, $150,150-156$.

[8] Bommarius, B., Jenssen, H., Elliott, M., Kindrachuk, J., Pasupuleti, M., Gieren, H., Jaeger, K. E., Hancock, R. E., \& Kalman, D. (2010). Cost-effective expression and purification of antimicrobial and host defense peptides in Escherichia coli. Peptides, 31, 1957-1965.

[9] Braff, M. H., Hawkins, M. A., Di Nardo, A., Lopez-Garcia, B., Howell, M. D., Wong, C., Lin, K., Streib, J. E., Dorschner, R., Leung, D. Y., et al. (2005). Structure-function relationships among human cathelicidin peptides: dissociation of antimicrobial properties from host immunostimulatory activities. J Immunol, 174, 4271-4278.

[10] Brocal, I., Falco, A., Mas, V., Rocha, A., Perez, L., Coll, J. M., \& Estepa, A. (2006). Stable expression of bioactive recombinant pleurocidin in a fish cell line. Appl Microbiol Biotechnol, 72, 1217-1228.

[11] Brogden, K. A. (2005). Antimicrobial peptides: pore formers or metabolic inhibitors in bacteria? Nat Rev Microbiol, 3, 238-250.

[12] Browne, M. J., Feng, C. Y., Booth, V., \& Rise, M. L. (2011). Characterization and expression studies of Gaduscidin-1 and Gaduscidin-2; paralogous antimicrobial peptide-like transcripts from Atlantic cod (Gadus morhua). Dev Comp Immunol, 35, 399-408.

[13] Bryksa, B. C., Mac, Donald. L. D., Patrzykat, A., Douglas, S. E., \& Mattatall, N. R. (2006). A C-terminal glycine suppresses production of pleurocidin as a fusion peptide in Escherichia coli. Prot Expr Purif, 45, 88-98.

[14] Burrowes, O. J., Diamond, G., \& Lee, T. C. (2005). Recombinant expression of pleurocidin cDNA using the Pichia pastoris expression system. J Biomed Biotechnol, 3, 74-384. 
[15] Burrowes, O. J., Hadjicharalambous, C., Diamond, G., \& Lee, T. C. (2004). Evaluation of antimicrobial spectrum and cytotoxic activity of pleurocidin for food applications. J Food Sci, 63, 66-71.

[16] Cardini, S., Dalli, J., Fineschi, S., Perretti, M., Lungarella, G., \& Lucattelli, M. (2012). Genetic ablation of the Fpr1 gene confers protection from smoking-induced lung emphysema in mice. Am J Respir Cell Mol Biol, PMID 22461430.

[17] Castle, M., Nazarian, A., Yi, S. S., \& Tempst, P. (1999). Lethal effects of apidaecin on Escherichia coli involve sequential molecular interactions with diverse targets. J Biol Chem, 274, 32555-32564.

[18] Cattaneo, F., Iaccio, A., Guerra, G., Montagnani, S., \& Ammendola, R. (2011). NADPH-oxidase-dependent reactive oxygen species mediate EGFR transactivation by FPRL1 in WKYMVm-stimulated human lung cancer cells. Free Radic Biol Med, 51, 1126-1136.

[19] Ceron, J. M., Contreras-Moreno, J., Puertollano, E., de Cienfuegos, G. A., Puertollano, M. A., \& de Pablo, M. A. (2010). The antimicrobial peptide cecropin A induces caspase-independent cell death in human promyelocytic leukemia cells. Peptides, 31, 1494-1503.

[20] Chang, T. W., Lin, Y. M., Wang, C. F., \& Liao, Y. D. (2012). Outer membrane lipoprotein Lpp is Gram-negative bacterial cell surface receptor for cationic antimicrobial peptides. J Biol Chem, 287, 418-428.

[21] Chen, Z., Wang, D., Cong, Y., Wang, J., Zhu, J., Yang, J., Hu, Z., Hu, X., Tan, Y., Hu, F., et al. (2011). Recombinant antimicrobial peptide hPAB-beta expressed in Pichia pastoris, a potential agent active against methicillin-resistant Staphylococcus aureus. Appl Microbiol Biotechnol, 89, 281-291.

[22] Cherkasov, A., Hilpert, K., Jenssen, H., Fjell, C. D., Waldbrook, M., Mullaly, S. C., Volkmer, R., \& Hancock, R. E. (2009). Use of artificial intelligence in the design of small peptide antibiotics effective against a broad spectrum of highly antibiotic-resistant superbugs. ACS Chem Biol, 4, 65-74.

[23] Chiou, P., Khoo, J., Bols, N. C., Douglas, S., \& Chen, T. T. (2006). Effects of linear cationic alpha-helical antimicrobial peptides on immune-relevant genes in trout macrophages. Dev Comp Immunol, 30, 797-806.

[24] Cho, J., \& Lee, D. G. (2011a). Oxidative stress by antimicrobial peptide pleurocidin triggers apoptosis in Candida albicans. Biochimie, 93, 1873-1879.

[25] Cho, J., \& Lee, D. G. (2011b). The antimicrobial peptide arenicin-1 promotes generation of reactive oxygen species and induction of apoptosis. Biochim Biophys Acta.

[26] Chou, H. T., Kuo, T. Y., Chiang, J. C., Pei, M. J., Yang, W. T., Yu, H. C., Lin, S. B., \& Chen, W. J. (2008). Design and synthesis of cationic antimicrobial peptides with improved activity and selectivity against Vibrio spp. Int J Antimicrob Agents, 32, 130-138. 
[27] Cirioni, O., Silvestri, C., Ghiselli, R., Giacometti, A., Orlando, F., Mocchegiani, F., Chiodi, L., Vittoria, A. D., Saba, V., \& Scalise, G. (2006). Experimental study on the efficacy of combination of alpha-helical antimicrobial peptides and vancomycin against Staphylococcus aureus with intermediate resistance to glycopeptides. Peptides , 27, 2600-2606.

[28] Cole, A. M., Darouiche, R. O., Legarda, D., Connell, N., \& Diamond, G. (2000). Characterization of a fish antimicrobial peptide: gene expression, subcellular localization, and spectrum of activity. Antimicrob Ag Chemother, 44, 2039-2045.

[29] Cole, A. M., Weis, P., \& Diamond, G. (1997). Isolation and characterization of pleurocidin, an antimicrobial peptide in the skin secretions of winter flounder. J Biol Chem, 272, 12008-12013.

[30] De Lucca, A. J., \& Walsh, T. J. (1999). Antifungal peptides: Novel therapeutic compounds against emerging pathogens. Antimicrob Ag Chemother, 43, 1-11.

[31] Dean, R. E., O’Brien, L. M., Thwaite, J. E., Fox, M. A., Atkins, H., \& Ulaeto, D. O. (2010). A carpet-based mechanism for direct antimicrobial peptide activity against vaccinia virus membranes. Peptides, 31, 1966-1972.

[32] den, Hertog. A. L., van Marle, J., van Veen, H. A., Van't, Hof. W., Bolscher, J. G., Veerman, E. C., \& Nieuw, Amerongen. A. V. (2005). Candidacidal effects of two antimicrobial peptides: histatin 5 causes small membrane defects, but LL-37 causes massive disruption of the cell membrane. Biochem J, 388, 689-695.

[33] Douglas, S. E., Gallant, J. W., Gong, Z., \& Hew, C. (2001). Cloning and developmental expression of a family of pleurocidin-like antimicrobial peptides from winter flounder, Pleuronectes americanus (Walbaum). Dev Comp Immunol, 25, 137-147.

[34] Douglas, S. E., Patrzykat, A., Pytyck, J., \& Gallant, J. W. (2003). Identification, structure and differential expression of novel pleurocidins clustered on the genome of the winter flounder, Pseudopleuronectes americanus (Walbaum). Eur J Biochem, 270, 3720-3730.

[35] Dunham, R. A., Warr, G. W., Nichols, A., Duncan, P. L., Argue, B., Middleton, D., \& Kucuktas, H. (2002). Enhanced bacterial disease resistance of transgenic channel catfish Ictalurus punctatus possessing cecropin genes. Mar Biotechnol, 4, 338-344.

[36] Eckert, R. (2011). Road to clinical efficacy: challenges and novel strategies for antimicrobial peptide development. Future Microbiol, 6, 635-651.

[37] Eckert, R., He, J., Yarbrough, D. K., Qi, F., Anderson, M. H., \& Shi, W. (2006). Targeted killing of Streptococcus mutans by a pheromone-guided "smart" antimicrobial peptide. Antimicrob Ag Chemother, 50, 3651-3657.

[38] Falla, T. J., \& Zhang, L. (2010). Efficacy of hexapeptide-7 on menopausal skin. J Drugs Dermatol, 9, 49-54. 
[39] Faraj, J. A., Dorati, R., Schoubben, A., Worthen, D., Selmin, F., Capan, Y., Leung, K., \& De Luca, P. P. (2007). Development of a peptide-containing chewing gum as a sustained release antiplaque antimicrobial delivery system. AAPS PharmSciTech, 26.

[40] Fehlbaum, P., Bulet, P., Chernysh, S., Briand, J. P., Roussel, J. P., Letellier, L., Hetru, C., \& Hoffmann, J. A. (1996). Structure-activity analysis of thanatin, a 21-residue inducible insect defense peptide with sequence homology to frog skin antimicrobial peptides. Proc Natl Acad Sci U S A, 93, 1221-1225.

[41] Feng, Z., Jiang, B., Chandra, J., Ghannoum, M., Nelson, S., \& Weinberg, A. (2005). Human beta-defensins: differential activity against candidal species and regulation by Candida albicans. J Dent Res, 84, 445-450.

[42] Fernandes, J. M., Ruangsri, J., \& Kiron, V. (2010). Atlantic cod piscidin and its diversification through positive selection. PLoS One , e9501., 5

[43] Fischer, P. M. (2003). The design, synthesis and application of stereochemical and directional peptide isomers: a critical review. Curr Protein Pept Sci, 4, 339-356.

[44] Fjell, C. D., Jenssen, H., Cheung, W. A., Hancock, R. E., \& Cherkasov, A. (2011). Optimization of antibacterial peptides by genetic algorithms and cheminformatics. Chem Biol Drug Des, 77, 48-56.

[45] Fjell, C. D., Jenssen, H., Hilpert, K., Cheung, W. A., Pante, N., Hancock, R. E., \& Cherkasov, A. (2009). Identification of novel antibacterial peptides by chemoinformatics and machine learning. J Med Chem, 52, 2006-2015.

[46] Gao, G., Lange, D., Hilpert, K., Kindrachuk, J., Zou, Y., Cheng, J. T., KazemzadehNarbat, M., Yu, K., Wang, R., Straus, S. K., et al. (2011). The biocompatibility and biofilm resistance of implant coatings based on hydrophilic polymer brushes conjugated with antimicrobial peptides. Biomaterials, 32, 3899-3909.

[47] Garlapati, S., Eng, N. F., Kiros, T. G., Kindrachuk, J., Mutwiri, G. K., Hancock, R. E., Halperin, S. A., Potter, A. A., Babiuk, L. A., \& Gerdts, V. (2011). Immunization with PCEP microparticles containing pertussis toxoid, CpG ODN and a synthetic innate defense regulator peptide induces protective immunity against pertussis. Vaccine, 29, 6540-6548.

[48] Ghiselli, R., Giacometti, A., Cirioni, O., Mocchegiani, F., Orlando, F., D'Amato, G., Sisti, V., Scalise, G., \& Saba, V. (2004). Cecropin B enhances betalactams activities in experimental rat models of gram-negative septic shock. Ann Surg, 239, 251-256.

[49] Goldman, M. J., Anderson, G. M., Stolzenberg, E. D., Kari, U. P., Zasloff, M., \& Wilson, J. M. (1997). Human beta-defensin-1 is a salt-sensitive antibiotic in lung that is inactivated in cystic fibrosis. Cell, 88, 553-560.

[50] Guaní-Guerra, E., Santos-Mendoza, T., Lugo-Reyes, S. O., \& Terán, L. M. (2010). Antimicrobial peptides: general overview and clinical implications in human health and disease. Clin Immunol, 135, 1-11. 
[51] Hadley, E. B., \& Hancock, R. E. (2010). Strategies for the discovery and advancement of novel cationic antimicrobial peptides. Curr Top Med Chem, 10, 1872-1881.

[52] Haines, L. R., Hancock, R. E. W., \& Pearson, T. W. (2003). Cationic antimicrobial peptide killing of African trypanosomes and Sodalis glossinidius, a bacterial symbiont of the insect vector of sleeping sickness. Vector-borne Zoonotic Dis, 3, 175-186.

[53] Haines, L. R., Thomas, J. M., Jackson, A. M., Eyford, B. A., Razavi, M., Watson, C. N., Gowen, B., Hancock, R. E., \& Pearson, T. W. (2009). Killing of trypanosomatid parasites by a modified bovine host defense peptide, BMAP-18. PLoS Negl Trop Dis, 3, e373.

[54] Hancock, R. E., \& Rozek, A. (2002). Role of membranes in the activities of antimicrobial cationic peptides. FEMS Microbiol Lett, 206, 143-149.

[55] Harrington, J. M. (2011). Antimicrobial peptide killing of African trypanosomes. Parasite Immunol, 33, 461-469.

[56] Helmerhorst, E. J., Troxler, R. F., \& Oppenheim, F. G. (2001). The human salivary peptide histatin 5 exerts its antifungal activity through the formation of reactive oxygen species. Proc Natl Acad Sci U S A, 98, 14637-14642.

[57] Hilchie, A. L., Doucette, C. D., Pinto, D. M., Patrzykat, A., Douglas, S., \& Hoskin, D. W. (2011). Pleurocidin-family cationic antimicrobial peptides are cytolytic for breast carcinoma cells and prevent growth of tumor xenografts. Breast Cancer Res, 13, R102 .

[58] Hilpert, K., Winkler, D. F., \& Hancock, R. E. (2007). Peptide arrays on cellulose support: SPOT synthesis, a time and cost efficient method for synthesis of large numbers of peptides in a parallel and addressable fashion. Nat Protoc, 2, 1333-1349.

[59] Hirsch, T., Spielmann, M., Zuhaili, B., Fossum, M., Metzig, M., Koehler, T., Steinau, H. U., Yao, F., Onderdonk, A. B., Steinstraesser, L., et al. (2009). Human beta-defensin-3 promotes wound healing in infected diabetic wounds. J Gene Med, 11, 220-228.

[60] Hoskin, D. W., \& Ramamoorthy, A. (2008). Studies on anticancer activities of antimicrobial peptides. Biochim Biophys Acta, 1778, 357-375.

[61] Hua, J., Yamarthy, R., Felsenstein, S., Scott, R. W., Markowitz, K., \& Diamond, G. (2010). Activity of antimicrobial peptide mimetics in the oral cavity: I. Activity against biofilms of Candida albicans. Mol Oral Microbiol, 25, 418-425.

[62] Huang, H. N., Pan, C. Y., Rajanbabu, V., Chan, Y. L., Wu, C. J., \& Chen, J. Y. (2011). Modulation of immune responses by the antimicrobial peptide, epinecidin (Epi)-1, and establishment of an Epi-1-based inactivated vaccine. Biomaterials, 32, 3627-3636.

[63] Huang, L. C., Jean, D., \& Mc Dermott, A. M. (2005). Effect of preservative-free artificial tears on the antimicrobial activity of human beta-defensin- 2 and cathelicidin LL-37 in vitro. Eye Contact Lens, 31, 34-38. 
[64] Hwang, B., Hwang, J. S., Lee, J., Kim, J. K., Kim, S. R., Kim, Y., \& Lee, D. G. (2011a). Induction of yeast apoptosis by an antimicrobial peptide, Papiliocin. Biochem Biophys Res Commun, 408, 89-93.

[65] Hwang, B., Hwang, J. S., Lee, J., \& Lee, D. G. (2011b). The antimicrobial peptide, psacotheasin induces reactive oxygen species and triggers apoptosis in Candida albicans. Biochem Biophys Res Commun, 405, 267-271.

[66] Imamura, T., Yasuda, M., Kusano, H., Nakashita, H., Ohno, Y., Kamakura, T., Taguchi, S., \& Shimada, H. (2010). Acquired resistance to the rice blast in transgenic rice accumulating the antimicrobial peptide thanatin. Transgenic Res, 19, 415-424.

[67] Imura, Y., Choda, N., \& Matsuzaki, K. (2008). Magainin 2 in action: distinct modes of membrane permeabilization in living bacterial and mammalian cells. Biophys J, 95, 5757-5765.

[68] Ingham, A. B., \& Moore, R. J. (2007). Recombinant production of antimicrobial peptides in heterologous microbial systems. Biotechnol Appl Biochem, 47, 1-9.

[69] Iwamuro, S., \& Kobayashi, T. (2010). An efficient protocol for DNA amplification of multiple amphibian skin antimicrobial peptide cDNAs. Methods Mol Biol, 615, 159-176.

[70] Jenssen, H., \& Hancock, R. E. (2009). Antimicrobial properties of lactoferrin. Biochimie, 91, 19-29.

[71] Jenssen, H., \& Hancock, R. E. (2010). Therapeutic potential of HDPs as immunomodulatory agents. Methods Mol Biol, 618, 329-347.

[72] Jiang, Z., Kullberg, B. J., van der Lee, H., Vasil, A. I., Hale, J. D., Mant, C. T., Hancock, R. E., Vasil, M. L., Netea, M. G., \& Hodges, R. S. (2008). Effects of hydrophobicity on the antifungal activity of alpha-helical antimicrobial peptides. Chem Biol Drug Des, 72, 483-495.

[73] Jin, F., Xu, X., Zhang, W., \& Gu, D. (2006). Expression and characterization of a housefly cecropin gene in the methylotrophic yeast, Pichia pastoris. Protein Expr Purif, 49, 39-46.

[74] Jin, X., Mei, H., Li, X., , Y., Zeng, A. H., Wang, Y., Lu, X., Chu, F., Wu, Q., \& Zhu, J. (2010). Apoptosis-inducing activity of the antimicrobial peptide cecropin of Musca domestica in human hepatocellular carcinoma cell line BEL-7402 and the possible mechanism. Acta Biochim Biophys Sin (Shanghai), 42, 259-265.

[75] Jung, H. J., Park, Y., Sung, W. S., Suh, B. K., Lee, J., Hahm, K. S., \& Lee, D. G. (2007). Fungicidal effect of pleurocidin by membrane-active mechanism and design of enantiomeric analogue for proteolytic resistance. Biochim Biophys Acta- Biomembranes, 1768, 1400-1405. 
[76] Kazemzadeh-Narbat, M., Kindrachuk, J., Duan, K., Jenssen, H., Hancock, R. E., \& Wang, R. (2010). Antimicrobial peptides on calcium phosphate-coated titanium for the prevention of implant-associated infections. Biomaterials, 31, 9519-9526.

[77] Kindrachuk, J., Jenssen, H., Elliott, M., Townsend, R., Nijnik, A., Lee, S. F., Gerdts, V., Babiuk, L. A., Halperin, S. A., \& Hancock, R. E. (2009). A novel vaccine adjuvant comprised of a synthetic innate defence regulator peptide and CpG oligonucleotide links innate and adaptive immunity. Vaccine, 27, 4662-4671.

[78] Kindrachuk, J., \& Napper, S. (2010). Structure-activity relationships of multifunctional host defence peptides. Mini Rev Med Chem, 10, 596-614.

[79] Knappe, D., Henklein, P., Hoffmann, R., \& Hilpert, K. (2010). Easy strategy to protect antimicrobial peptides from fast degradation in serum. Antimicrob Ag Chemother, 54, 4003-4005.

[80] Koczulla, R., von, Degenfeld. G., Kupatt, C., Krotz, F., Zahler, S., Gloe, T., Issbrucker, K., Unterberger, P., Zaiou, M., Lebherz, C., et al. (2003). An angiogenic role for the human peptide antibiotic LL-37/hCAP-18. J Clin Invest, 111, 1665-1672.

[81] Lai, Y., \& Gallo, R. L. (2009). AMPed up immunity: how antimicrobial peptides have multiple roles in immune defense. Trends Immunol, 30, 131-141.

[82] Lan, Y., Ye, Y., Kozlowska, J., Lam, J. K., Drake, A. F., \& Mason, A. J. (2010). Structural contributions to the intracellular targeting strategies of antimicrobial peptides. Biochim Biophys Acta, 1798, 1934-1943.

[83] Lange, C. F., Hancock, R. E., Samuel, J., \& Finlay, W. H. (2001). In vitro aerosol delivery and regional airway surface liquid concentration of a liposomal cationic peptide. J Pharm Sci, 90, 1647-1657.

[84] Lee, J., \& Lee, D. G. (2008). Structure-antimicrobial activity relationship between pleurocidin and its enantiomer. Exp Mol Med, 40, 370-376.

[85] Lee, J., \& Lee, D. G. (2010). Influence of the hydrophobic amino acids in the N- and C-terminal regions of pleurocidin on antifungal activity. J Microbiol Biotechnol, 20, 1192-1195.

[86] Leontiadou, H., Mark, A. E., \& Marrink, S. J. (2006). Antimicrobial peptides in action. J Am Chem Soc, 128, 12156-12161.

[87] Li, J. F., Zhang, J., Song, R., Zhang, J. X., Shen, Y., \& Zhang, S. Q. (2009). Production of a cytotoxic cationic antibacterial peptide in Escherichia coli using SUMO fusion partner. Appl Microbiol Biotechnol, 84, 383-388.

[88] Li, L., He, J., Eckert, R., Yarbrough, D., Lux, R., Anderson, M., \& Shi, W. (2010). Design and characterization of an acid-activated antimicrobial peptide. Chem Biol Drug Des, 75, 127-132. 
[89] Li, M., Lai, Y., Villaruz, A. E., Cha, D. J., Sturdevant, D. E., \& Otto, M. (2007). Grampositive three-component antimicrobial peptide-sensing system. Proc Natl Acad Sci $U$ $S A, 104,9469-9474$.

[90] Li, M., Yu, D. H., \& Cai, H. (2008). The synthetic antimicrobial peptide KLKL5KLK enhances the protection and efficacy of the combined DNA vaccine against Mycobacterium tuberculosis. DNA Cell Biol, 27, 405-413.

[91] Lienkamp, K., Madkour, A. E., Musante, A., Nelson, C. F., Nusslein, K., \& Tew, G. N. (2008). Antimicrobial polymers prepared by ROMP with unprecedented selectivity: a molecular construction kit approach. J Am Chem Soc, 130, 9836-9843.

[92] Lim, S. S., Song, Y. M., Jang, M. H., Kim, Y., Hahm, K. S., \& Shin, S. Y. (2004a). Effects of two glycine residues in positions 13 and 17 of pleurocidin on structure and bacterial cell selectivity. Protein Pept Lett, 11, 35-40.

[93] Lipsky, B. A., Holroyd, K. J., \& Zasloff, M. (2008). Topical versus systemic antimicrobial therapy for treating mildly infected diabetic foot ulcers: a randomized, controlled, double-blinded, multicenter trial of pexiganan cream. Clin Infect Dis, 47, 1537-1545.

[94] Liu, S., Yang, H., Wan, L., Cai, H. W., Li, S. F., Li, Y. P., Cheng, J. Q., \& Lu, X. F. (2011). Enhancement of cytotoxicity of antimicrobial peptide magainin II in tumor cells by bombesin-targeted delivery. Acta Pharmacol Sin, 32, 79-88.

[95] Lynn, M. A., Kindrachuk, J., Marr, A. K., Jenssen, H., Pante, N., Elliott, M. R., Napper, S., Hancock, R. E., \& Mc Master, W. R. (2011). Effect of BMAP-28 antimicrobial peptides on Leishmania major promastigote and amastigote growth: role of leishmanolysin in parasite survival. PLoS Negl Trop Dis, 5, e1141.

[96] Mader, J. S., Ewen, C., Hancock, R. E., \& Bleackley, R. C. (2011). The human cathelicidin, LL-37, induces granzyme-mediated apoptosis in regulatory T cells. J Immunother, 34, 229-235.

[97] Mai, J., Tian, X. L., Gallant, J. W., Merkley, N., Biswas, Z., Syvitski, R., Douglas, S. E., Ling, J., \& Li, Y. H. (2011). A novel target-specific, salt-resistant antimicrobial peptide against the cariogenic pathogen Streptococcus mutans. Antimicrob Ag Chemother.

[98] Makovitzki, A., Fink, A., \& Shai, Y. (2009). Suppression of human solid tumor growth in mice by intratumor and systemic inoculation of histidine-rich and $\mathrm{pH}$-dependent host defense-like lytic peptides. Cancer Res, 69, 3458-3463.

[99] Marcos, J. F., \& Gandia, M. (2009). Antimicrobial peptides: to membranes and beyond. Expert Opin Drug Discov, 4, 659-671.

[100] Marsh, E. N., Buer, B. C., \& Ramamoorthy, A. (2009). Fluorine--a new element in the design of membrane-active peptides. Mol Biosyst, 5, 1143-1147. 
[101] Mason, A. J., Chotimah, I. N., Bertani, P., \& Bechinger, B. (2006). A spectroscopic study of the membrane interaction of the antimicrobial peptide pleurocidin. Mol Membr Biol, 23, 185-194.

[102] Mason, A. J., Marquette, A., \& Bechinger, B. (2007). Zwitterionic phospholipids and sterols modulate antimicrobial peptide-induced membrane destabilization. Biophys J, 93, 4289-4299.

[103] Mc Bride, S. M., \& Sonenshein, A. L. (2011). Identification of a genetic locus responsible for antimicrobial peptide resistance in Clostridium difficile. Infect Immun, 79, $167-176$.

[104] Mc Phee, J. B., \& Hancock, R. E. (2005). Function and therapeutic potential of host defence peptides. J Pept Sci, 11, 677-687.

[105] Mc Phee, J. B., Lewenza, S., \& Hancock, R. E. (2003). Cationic antimicrobial peptides activate a two-component regulatory system, PmrA-PmrB, that regulates resistance to polymyxin B and cationic antimicrobial peptides in Pseudomonas aeruginosa. $\mathrm{Mol}$ Microbiol, 50, 205-217.

[106] Menard, S., Forster, V., Lotz, M., Gutle, D., Duerr, C. U., Gallo, R. L., Henriques-Normark, B., Putsep, K., Andersson, M., Glocker, E. O., et al. (2008). Developmental switch of intestinal antimicrobial peptide expression. J Exp Med, 205, 183-193.

[107] Mogi, T., \& Kita, K. (2009). Gramicidin S and polymyxins: the revival of cationic cyclic peptide antibiotics. Cell Mol Life Sci, 66, 3821-3826.

[108] Mor, A. (2009). Multifunctional host defense peptides: antiparasitic activities. FEBS J, $276,6474-6482$.

[109] Morash, M. G., Douglas, S. E., Robotham, A., Ridley, C. M., Gallant, J. W., \& Soanes, K. H. (2011). The zebrafish embryo as a tool for screening and characterizing pleurocidin host-defense peptides as anti-cancer agents. Dis Model Mech, 4, 622-633.

[110] Morton, C. O., Dos, Santos. S. C., \& Coote, P. (2007a). An amphibian-derived, cationic, alpha-helical antimicrobial peptide kills yeast by caspase-independent but AIF-dependent programmed cell death. Mol Microbiol, 65, 494-507.

[111] Morton, C. O., Hayes, A., Wilson, M., Rash, B. M., Oliver, S. G., \& Coote, P. (2007b). Global phenotype screening and transcript analysis outlines the inhibitory mode(s) of action of two amphibian-derived, alpha-helical, cationic peptides on Saccharomyces cerevisiae. Antimicrob Ag Chemother, 51, 3948-3959.

[112] Murakami, T., Nakajima, T., Koyanagi, Y., Tachibana, K., Fujii, N., Tamamura, H., Yoshida, N., Waki, M., Matsumoto, A., Yoshie, O., et al. (1997). A small molecule CXCR4 inhibitor that blocks T cell line-tropic HIV-1 infection. J Exp Med, 186, 1389-1393. 
[113] Murray, H. M., Leggiadro, C. T., \& Douglas, S. E. (2007). Immunocytochemical localization of pleurocidin to the cytoplasmic granules of eosinophilic granular cells from the winter flounder gill. J Fish Biol, 70, 336-345.

[114] Mutwiri, G., Gerdts, V., Lopez, M., \& Babiuk, L. A. (2007). Innate immunity and new adjuvants. Rev Sci Tech, 26, 147-156.

[115] Nguyen, L. T., Chau, J. K., Perry, N. A., de Boer, L., Zaat, S. A., \& Vogel, H. J. (2010). Serum stabilities of short tryptophan- and arginine-rich antimicrobial peptide analogs. PLoS One, 5, e12684.

[116] Nguyen, L. T., Haney, E. F., \& Vogel, H. J. (2011). The expanding scope of antimicrobial peptide structures and their modes of action. Trends Biotechnol , 29, 464-472.

[117] Nicolas, P. (2009). Multifunctional host defense peptides: intracellular-targeting antimicrobial peptides. FEBS J, 276, 6483-6496.

[118] Nijnik, A., \& Hancock, R. E. (2009). Host defence peptides: antimicrobial and immunomodulatory activity and potential applications for tackling antibiotic-resistant infections. Emerg Health Threats J, 2, e1-7.

[119] Nizet, V. (2006). Antimicrobial peptide resistance mechanisms of human bacterial pathogens. Curr Issues Mol Biol, 8, 11-26.

[120] Noga, E. J., Ullal, A. J., Corrales, J., \& Fernandes, J. M. (2011). Application of antimicrobial polypeptide host defenses to aquaculture: Exploitation of downregulation and upregulation responses. Comp Biochem Physiol Part D Genomics Proteomics, 6, 44-54.

[121] Oono, T., Shirafuji, Y., Huh, W. K., Akiyama, H., \& Iwatsuki, K. (2002). Effects of human neutrophil peptide- 1 on the expression of interstitial collagenase and type I collagen in human dermal fibroblasts. Arch Dermatol Res, 294, 185-189.

[122] Park, C. B., Yi, K. S., Matsuzaki, K., Kim, M. S., \& Kim, S. C. (2000). Structure-activity analysis of buforin $\mathrm{II}$, a histone $\mathrm{H} 2 \mathrm{~A}$-derived antimicrobial peptide: the proline hinge is responsible for the cell-penetrating ability of buforin II. Proc Natl Acad Sci U S A, $97,8245-8250$.

[123] Park, Y., Park, S. C., Kim, J. Y., Park, J. O., Seo, C. H., Nah, J. W., \& Hahm, K. S. (2010). In vitro efficacy of a synthetic all-d antimicrobial peptide against clinically isolated drug-resistant strains. Int J Antimicrob Agents, 35, 208-209.

[124] Patrzykat, A., Friedrich, C. L., Zhang, L., Mendoza, V., \& Hancock, R. E. (2002). Sublethal concentrations of pleurocidin-derived antimicrobial peptides inhibit macromolecular synthesis in Escherichia coli. Antimicrob Ag Chemother, 46, 605-614.

[125] Patrzykat, A., Gallant, J. W., Seo, J. K., Pytyck, J., \& Douglas, S. E. (2003). Novel antimicrobial peptides derived from flatfish genes. Antimicrob Ag Chemother, 47, 2464-2470. 
[126] Patrzykat, A., Zhang, L., Mendoza, V., Iwama, G. K., \& Hancock, R. E. (2001). Synergy of histone-derived peptides of coho salmon with lysozyme and flounder pleurocidin. Antimicrob Agents Chemother, 45, 1337-1342.

[127] Peschel, A., \& Sahl, H. G. (2006). The co-evolution of host cationic antimicrobial peptides and microbial resistance. Nat Rev Microbiol, 4, 529-536.

[128] Pieters, R. J., Arnusch, C. J., \& Breukink, E. (2009). Membrane permeabilization by multivalent anti-microbial peptides. Protein Pept Lett, 16, 736-742.

[129] Projan, S. J., \& Bradford, P. A. (2007). Late stage antibacterial drugs in the clinical pipeline. Curr Opin Microbiol, 10, 441-446.

[130] Redfern, R. L., Reins, R. Y., \& Mc Dermott, A. M. (2011). Toll-like receptor activation modulates antimicrobial peptide expression by ocular surface cells. Exp Eye Res, 92, 209-220.

[131] Riedl, S., Rinner, B., Asslaber, M., Schaider, H., Walzer, S., Novak, A., Lohner, K., \& Zweytick, D. (2011). In search of a novel target- phosphatidylserine exposed by nonapoptotic tumor cells and metastases of malignancies with poor treatment efficacy. Biochim Biophys Acta, 1808, 2638-2645.

[132] Risso, A., Zanetti, M., \& Gennaro, R. (1998). Cytotoxicity and apoptosis mediated by two peptides of innate immunity. Cell Immunol, 189, 107-115.

[133] Rotem, S., \& Mor, A. (2009). Antimicrobial peptide mimics for improved therapeutic properties. Biochim Biophys Acta, 1788, 1582-1592.

[134] Roy, S., \& Das, P. K. (2008). Antibacterial hydrogels of amino acid-based cationic amphiphiles. Biotechnol Bioeng , 100, 756-764.

[135] Sa'adedin, F., \& Bradshaw, J. P. (2010). A differential scanning calorimetry study of the effects and interactions of antimicrobial peptide LS3 on phosphatidylethanolamine bilayers. Protein Pept Lett, 17, 1345-1350.

[136] Saint, N., Cadiou, H., Bessin, Y., \& Molle, G. (2002). Antibacterial peptide pleurocidin forms ion channels in planar lipid bilayers. Biochim Biophys Acta, 1564, 359-364.

[137] Schutte, B. C., Mitros, J. P., Bartlett, J. A., Walters, J. D., Jia, H. P., Welsh, M. J., Casavant, T. L., \& Mc Cray, P. B., Jr. (2002). Discovery of five conserved beta-defensin gene clusters using a computational search strategy. Proc Natl Acad Sci U S A, 99, 2129-2133.

[138] Scott, R. W., De Grado, W. F., \& Tew, G. N. (2008). De novo designed synthetic mimics of antimicrobial peptides. Curr Opin Biotechnol, 19, 620-627.

[139] Selsted, M. E., \& Ouellette, A. J. (2005). Mammalian defensins in the antimicrobial immune response. Nat Immunol, 6, 551-557. 
[140] Selvatici, R., Falzarano, S., Mollica, A., \& Spisani, S. (2006). Signal transduction pathways triggered by selective formylpeptide analogues in human neutrophils. Eur J Pharmacol, 534, 1-11.

[141] Shai, Y. (2002). Mode of action of membrane active antimicrobial peptides. Biopolymers, 66, 236-248.

[142] Shai, Y., Makovitzky, A., \& Avrahami, D. (2006). Host defense peptides and lipopeptides: modes of action and potential candidates for the treatment of bacterial and fungal infections. Curr Protein Pept Sci, 7, 479-486.

[143] Shen, C. J., Kuo, T. Y., Lin, C. C., Chow, L. P., \& Chen, W. J. (2010). Proteomic identification of membrane proteins regulating antimicrobial peptide resistance in Vibrio parahaemolyticus. J Appl Microbiol, 108, 1398-1407.

[144] Splith, K., \& Neundorf, I. (2011). Antimicrobial peptides with cell-penetrating peptide properties and vice versa. Eur Biophys J, 40, 387-397.

[145] Steinstraesser, L., Burghard, O., Nemzek, J., Fan, M. H., Merry, A., Remick, D. I., Su, G. L., Steinau, H. U., \& Wang, S. C. (2003). Protegrin-1 increases bacterial clearance in sepsis but decreases survival. Crit Care Med, 31, 221-226.

[146] Steinstraesser, L., Koehler, T., Jacobsen, F., Daigeler, A., Goertz, O., Langer, S., Kesting, M., Steinau, H., Eriksson, E., \& Hirsch, T. (2008). Host defense peptides in wound healing. Mol Med, 14, 528-537.

[147] Sullivan, R., Santarpia, P., Lavender, S., Gittins, E., Liu, Z., Anderson, M. H., He, J., Shi, W., \& Eckert, R. (2011). Clinical efficacy of a specifically targeted antimicrobial peptide mouth rinse: Targeted elimination of Streptococcus mutans and prevention of demineralization. Caries Res, 45, 415-428.

[148] Sun, B. J., Xie, H. X., Song, Y., \& Nie, P. (2007). Gene structure of an antimicrobial peptide from mandarin fish, Siniperca chuatsi (Basilewsky), suggests that moronecidins and pleurocidins belong in one family: the piscidins. J Fish Dis, 30, 335-343.

[149] Sung, W. S., \& Lee, D. G. (2008). Pleurocidin-derived antifungal peptides with selective membrane-disruption effect. Biochem Biophys Res Commun, 369, 858-861.

[150] Syvitski, R. T., Burton, I., Mattatall, N. R., Douglas, S. E., \& Jakeman, D. L. (2005). Structural characterization of the antimicrobial peptide pleurocidin from winter flounder. Biochemistry, 44, 7282-7293.

[151] Talukder, P., Satho, T., Irie, K., Sharmin, T., Hamady, D., Nakashima, Y., Kashige, N., \& Miake, F. (2011). Trace metal zinc stimulates secretion of antimicrobial peptide LL-37 from Caco-2 cells through ERK and 38MAP kinase. Int Immunopharmacol 11, 141-144.

[152] Tani, K., Shimizu, T., Kida, Y., \& Kuwano, K. (2011). Mycoplasma pneumoniae infection induces a neutrophil-derived antimicrobial peptide, cathelin-related antimicrobial peptide. Microbiol Immunol, 55, 582-588. 
[153] Tao, R., Tong, Z., Lin, Y., Xue, Y., Wang, W., Kuang, R., Wang, P., Tian, Y., \& Ni, L. (2011). Antimicrobial and antibiofilm activity of pleurocidin against cariogenic microorganisms. Peptides, 32, 1748-1754.

[154] Tavano, R., Segat, D., Gobbo, M., \& Papini, E. (2011). The honeybee antimicrobial peptide apidaecin differentially immunomodulates human macrophages, monocytes and dendritic cells. J Innate Immun.

[155] Tay, D. K., Rajagopalan, G., Li, X., Chen, Y., Lua, L. H., \& Leong, S. S. (2011). A new bioproduction route for a novel antimicrobial peptide. Biotechnol Bioeng, 108, 572-581.

[156] Tokumaru, S., Sayama, K., Shirakata, Y., Komatsuzawa, H., Ouhara, K., Hanakawa, Y., Yahata, Y., Dai, X., Tohyama, M., Nagai, H., et al. (2005). Induction of keratinocyte migration via transactivation of the epidermal growth factor receptor by the antimicrobial peptide LL-37. J Immunol, 175, 4662-4668.

[157] Tomasinsig, L., Scocchi, M., Mettulio, R., \& Zanetti, M. (2004). Genome-wide transcriptional profiling of the Escherichia coli response to a proline-rich antimicrobial peptide. Antimicrob Agents Chemother, 48, 3260-3267.

[158] Torrent, M., Andreu, D., Nogues, V. M., \& Boix, E. (2011). Connecting peptide physicochemical and antimicrobial properties by a rational prediction model. PLoS One , 6, e16968.

[159] Tosteson, M. T., Holmes, S. J., Razin, M., \& Tosteson, D. C. (1985). Melittin lysis of red cells. J Membr Biol, 87, 35-44.

[160] Turkoglu, O., Kandiloglu, G., Berdeli, A., Emingil, G., \& Atilla, G. (2011). Antimicrobial peptide hCAP-18/LL-37 protein and mRNA expressions in different periodontal diseases. Oral Dis, 17, 60-67.

[161] van Beek, W. P., Smets, L. A., \& Emmelot, P. (1973). Increased sialic acid density in surface glycoprotein of transformed and malignant cells--a general phenomenon? Cancer Res, 33, 2913-2922.

[162] van der Does, A. M., Bogaards, S. J., Ravensbergen, B., Beekhuizen, H., van Dissel, J. T., \& Nibbering, P. H. (2010). Antimicrobial peptide hLF1-11 directs granulocytemacrophage colony-stimulating factor-driven monocyte differentiation toward macrophages with enhanced recognition and clearance of pathogens. Antimicrob Ag Chemother, 54, 811-816.

[163] Venugopal, D. (2010). Novel antimicrobial peptides that exhibit activity against select agents and other drug resistant bacteria. Bioorg Med Chem, 18, 5137-5147.

[164] Vylkova, S., Nayyar, N., Li, W., \& Edgerton, M. (2007). Human beta-defensins kill Candida albicans in an energy-dependent and salt-sensitive manner without causing membrane disruption. Antimicrob Agents Chemother, 51, 154-161. 
[165] Wallace, D. F., Jones, M. D., Pedersen, P., Rivas, L., Sly, L. I., \& Subramaniam, V. N. (2006). Purification and partial characterisation of recombinant human hepcidin. Biochimie, 88, 31-37.

[166] Walsh, E. G., Maher, S., Devocelle, M., O’Brien, P. J., Baird, A. W., \& Brayden, D. J. (2011). High content analysis to determine cytotoxicity of the antimicrobial peptide, melittin and selected structural analogs. Peptides, 32, 1764-1773.

[167] Wang, C., Li, H. B., Li, S., Tian, L. L., \& Shang, D. J. (2011). Antitumor effects and cell selectivity of temporin-1CEa, an antimicrobial peptide from the skin secretions of the Chinese brown frog (Rana chensinensis). Biochimie.

[168] Wang, G., Watson, K. M., Peterkofsky, A., \& Buckheit, R. W., Jr. (2010). Identification of novel human immunodeficiency virus type 1-inhibitory peptides based on the antimicrobial peptide database. Antimicrob Ag Chemother, 54, 1343-1346.

[169] Wehkamp, J., Harder, J., Weichenthal, M., Mueller, O., Herrlinger, K. R., Fellermann, K., Schroeder, J. M., \& Stange, E. F. (2003). Inducible and constitutive beta-defensins are differentially expressed in Crohn's disease and ulcerative colitis. Inflamm Bowel Dis, 9, 215-223.

[170] White, J. H. (2010). Vitamin D as an inducer of cathelicidin antimicrobial peptide expression: past, present and future. J Steroid Biochem Mol Biol, 121, 234-238.

[171] Wiesner, J., \& Vilcinskas, A. (2010). Antimicrobial peptides: the ancient arm of the human immune system. Virulence, 1, 440-464.

[172] Williams, K. J., \& Bax, R. P. (2009). Challenges in developing new antibacterial drugs. Curr Opin Investig Drugs, 10, 157-163.

[173] Won, A., Khan, M., Gustin, S., Akpawu, A., Seebun, D., Avis, T. J., Leung, B. O., Hitchcock, A. P., \& Ianoul, A. (2011a). Investigating the effects of L- to D-amino acid substitution and deamidation on the activity and membrane interactions of antimicrobial peptide anoplin. Biochim Biophys Acta, 1808, 1592-1600.

[174] Won, H. S., Kang, S. J., Choi, W. S., \& Lee, B. J. (2011b). Activity optimization of an undecapeptide analogue derived from a frog-skin antimicrobial peptide. Mol Cells, 31, 49-54.

[175] Wu, G., Li, X., Deng, X., Fan, X., Wang, S., Shen, Z., \& Xi, T. (2011). Protective effects of antimicrobial peptide $S$-thanatin against endotoxic shock in mice introduced by LPS. Peptides, 32, 353-357.

[176] Yala, J. F., Thebault, P., Hequet, A., Humblot, V., Pradier, C. M., \& Berjeaud, J. M. (2011). Elaboration of antibiofilm materials by chemical grafting of an antimicrobial peptide. Appl Microbiol Biotechnol, 89, 623-634.

[177] Yang, D., Chen, Q., Schmidt, A. P., Anderson, G. M., Wang, J. M., Wooters, J., Oppenheim, J. J., \& Chertov, O. (2000). LL-37, the neutrophil granule- and epithelial cell-derived cathelicidin, utilizes formyl peptide receptor-like 1 (FPRL1) as a receptor to 
chemoattract human peripheral blood neutrophils, monocytes, and T cells. J Exp Med, $192,1069-1074$.

[178] Yang, J. Y., Shin, S. Y., Lim, S. S., Hahm, K. S., \& Kim, Y. (2006). Structure and bacterial cell selectivity of a fish-derived antimicrobial peptide, pleurocidin. J Microbiol Biotechnol, 16, 880-888.

[179] Yang, K., Gitter, B., Ruger, R., Wieland, G. D., Chen, M., Liu, X., Albrecht, V., \& Fahr, A. (2011). Antimicrobial peptide-modified liposomes for bacteria targeted delivery of temoporfin in photodynamic antimicrobial chemotherapy. Photochem Photobiol Sci, $10,1593-1560$.

[180] Yarus, S., Rosen, J. M., Cole, A. M., \& Diamond, G. (1996). Production of active bovine tracheal antimicrobial peptide in milk of transgenic mice. Proc Natl Acad Sci U S A, 93, 14118-14121.

[181] Yeung, A. T., Gellatly, S. L., \& Hancock, R. E. (2011). Multifunctional cationic host defence peptides and their clinical applications. Cell Mol Life Sci, 68, 2161-2176.

[182] Yevtushenko, D. P., Romero, R., Forward, B. S., Hancock, R. E., Kay, W. W., \& Misra, S. (2005). Pathogen-induced expression of a cecropin A-melittin antimicrobial peptide gene confers antifungal resistance in transgenic tobacco. J Exp Bot, 56, 1685-1695.

[183] Yoon, W. H., Park, H. D., Lim, K., \& Hwang, B. D. (1996). Effect of O-glycosylated mucin on invasion and metastasis of HM7 human colon cancer cells. Biochem Biophys Res Commun, 222, 694-699.

[184] Yoshida, K., Mukai, Y., Niidome, T., Takashi, C., Tokunaga, Y., Hatakeyama, Y., \& Aoyagi, H. (2001). Interaction of pleurocidin and its analogs with phospholipid membrane and their antibacterial activity. J Pept Res, 57, 119-126.

[185] Zasloff, M. (2002). Antimicrobial peptides of multicellular organisms. Nature, 415, 389-395.

[186] Zasloff, M. (2006). Inducing endogenous antimicrobial peptides to battle infections. Proc Natl Acad Sci U S A, 103, 8913-8914.

[187] Zhang, J., Yang, Y., Teng, D., Tian, Z., Wang, S., \& Wang, J. (2011). Expression of plectasin in Pichia pastoris and its characterization as a new antimicrobial peptide against Staphyloccocus and Streptococcus. Protein Expr Purif, 78, 189-196.

[188] Zhang, L., \& Falla, T. J. (2010). Potential therapeutic application of host defense peptides. Methods Mol Biol, 618, 303-327. 
